\title{
A TRAJECTORY-TRACKING CONTROLLER FOR IMPROVING THE SAFETY AND STABILITY OF FOUR-WHEEL STEERING AUTONOMOUS VEHICLES
}

\author{
Runqiao LIU ${ }^{1}$, Minxiang WEI ${ }^{*}$, Nan $\mathrm{SANG}^{3}$, Jianwei WEI ${ }^{4}$ \\ ${ }^{1,2}$ Dept of Vehicle Engineering, Nanjing University of Aeronautics and Astronautics, Nanjing, Jiangsu, China \\ ${ }^{3}$ Dept of Vehicle Engineering, Changzhou Institute of Technology, Changzhou, Jiangsu, China \\ ${ }^{4}$ Dept of Automotive Engineering, Ningbo University of Technology, Ningbo, Zhejiang, China
}

Submitted 26 September 2019; resubmitted 28 April 2020, 21 June 2020; accepted 27 July 2020;

first published online 12 March 2021

\begin{abstract}
To achieve anti-crosswind, anti-sideslip, and anti-rollover in trajectory-tracking for Four-Wheel Steering (4WS) autonomous vehicles, a trajectory-tracking controller based on a four-channel Active Disturbance Rejection Control (ADRC) was used to track the desired lateral displacement, longitudinal displacement, yaw angle, and roll angle, and minimize the tracking errors between the actual output values and the desired values through static decoupling steering and braking systems. In addition, the anti-crosswind, anti-sideslip, and anti-rollover simulations were implemented with $\mathrm{CarSim}^{\circledR}$. Finally, the simulation results showed that the 4WS autonomous vehicle with the controller still has good anti-crosswind, anti-sideslip, and anti-rollover performance in path tracking, even under a small turning radius or lowadhesion curved roads.
\end{abstract}

Keywords: four-wheel steering, curved trajectory-tracking, active disturbance rejection control, anti-crosswind, anti-sideslip, anti-rollover, $\mathrm{CarSim}^{\circledR}$.

\section{Introduction}

Autonomous vehicles often encounter extreme conditions in trajectory-tracking, such as crosswinds, high-speed driving, small turning radius, and low-adhesion curved roads. The question of how to improve the safety and stability of autonomous vehicles while achieving accurate trajectory-tracking under these extreme conditions is critical (Sun et al. 2018).

Crosswinds occur in areas with good air mobility, such as open plains, bridges, tunnel entrances and exits, mountains, and the seaside. When the vehicle encounters strong crosswinds, the body will sway left and right or even drift off (Maruyama, Yamazaki 2006). In terms of anti-crosswind, Demirci and Gokasan (2013) used an adaptively optimized distribution method that properly distributes the yaw moment to prevent vehicles from drifting off due to crosswinds. Nagai et al. (2002) designed a coordinated control system based on optimal control theory for the steering angle and braking force to improve the anti-crosswind performance. Rollover is divided into two categories: tripped rollover and un-tripped rollover. The un-tripped rollover refers to the rollover caused by excessive lateral acceleration during high-speed emergency steering. To increase under-steer and prevent vehicle rollover, the most common way is to reduce the yaw rate through Direct Yaw-moment Control (DYC) or active steering control in addition to reducing vehicle speed (Yim et al. 2012). In Chiu et al. (2010), a robust rollover prevention controller based on differential braking showed good anti-rollover performance in an elk-test. In Zhao and Taheri (2012), a multi-objective anti-roll control system was used to improve the anti-rollover performance of heavy vehicles.

A small turning radius and low-adhesion curved road can affect the trajectory-tracking performance of autonomous vehicles (Li, Yu 2010). Four-Wheel Steering (4WS) or DYC is generally an effective measure to improve the trajectory-tracking performance of vehicles under these curved roads. First, when it comes to vehicles with 4WS, to prevent them from losing steering ability and reduce the sideslip, their yaw rate response is generally set to a first-order lag response, and their sideslip angle response

*Corresponding author. E-mail: vbe@nuaa.edu.cn 
is generally set to 0 (Shibahata et al. 1986; Furukawa et al. 1989; Sano et al. 1986; Nikravesh, Lee 1993). In Hiraoka et al. (2004); Kazemi and Shirazi (2012); Zhang et al. (2018), a trajectory-tracking controller based on sliding mode control was used to improve the stability and safety performance of the $4 \mathrm{WS}$ vehicle in trajectory-tracking under different speeds and road conditions. In Liu et al. (2018), a trajectory-tracking controller consisting of 4WS feed-forward and Linear Quadratic Regulator (LQR) feedback was used to improve tire lateral force saturation and reduce $4 \mathrm{WS}$ vehicle sideslip under high-speed emergency obstacle avoidance. Second, for vehicles with DYC, a DYC based on fuzzy logic was used to improve the safety and stability of $4 \mathrm{WS}$ vehicles by tracking the desired yaw rate and sideslip angle under different road adhesion coefficients in (Zeyada et al. 1998; Boada et al. 2005; Sun et al. 2013). In (Li et al. 2012; Ji et al. 2014), a DYC based on Model Predictive Control (MPC) was used to enhance the 4WS vehicle stability in a critical running condition. Finally, for vehicles with 4WS and DYC coordinated control, an integrated control system of 4WS and DYC based on a model matching controller was used to follow the desired dynamic model in research by Nagai et al. (1997). In works by Zhou et al. (2009); Song (2012), a 4WS and DYC integrated control system based on fuzzy control was used to improve the stability and safety of $4 \mathrm{WS}$ vehicles at highspeeds. Zhu and Zong (2009) used an integrated control of $4 \mathrm{WS}$ and DYC based on optimal control to improve the safety and stability of $4 \mathrm{WS}$ vehicles by tracking the desired sideslip angle and yaw rate.

At present, there are several common trajectorytracking control methods for autonomous vehicles: the trajectory-tracking control method based on geometric kinematics, the trajectory-tracking control method based on vehicle dynamics and the trajectory-tracking control method based on fuzzy neural network. The most popular trajectory-tracking control methods based on geometric kinematics are "pure pursuit" trajectory-tracking control methods and "stanley control" trajectory-tracking control methods. These control methods can eliminate the lateral displacement deviation of the vehicle by adjusting the Front-Wheel Steering (FWS) angle. However, due to ignoring the changes in the rotational inertia, tire longitudinal stiffness, tire corner stiffness, and tire vertical load and other vehicle parameters, the trajectory-tracking performance of the vehicle based on these control methods under high-speed and sharp steering conditions has been reduced (Hoffmann et al. 2007; Urmson et al. 2009; Yang et al. 2017). The most popular trajectory-tracking control methods based on vehicle dynamics are the optimal preview trajectory-tracking control method and the MPC trajectory-tracking control method. These control methods also eliminate the lateral displacement deviation of the vehicle by adjusting the FWS angle. However, there are great difficulties in the selection of control parameters such as preview time, predicted time domain, or control time domain (MacAdam 1980; Ming et al. 2016).
The fuzzy control rules of the trajectory-tracking control method based on fuzzy neural network come from a lot of neural network training. This control method can eliminate the lateral displacement deviation of the vehicle by adjusting the FWS angle in the steering system, and can also eliminate the yaw angle deviation of the vehicle by the braking force in the braking system. However, this control method requires a large number of accurate training data samples, and there is a large subjectivity in generating fuzzy control rules (Li, Gao 2006; Duong et al. 2018).

As we all know, the steering and braking systems of vehicles are nonlinear and coupled. Although the above LQR, fuzzy neural network, sliding mode, and MPC controls have significant inhibitory effects on external disturbances, they still have some limitations with regard to the control of non-linear and coupled systems (Ren et al. 2011; Cheng et al. 2011; Chen et al. 2018). To solve the non-linear and coupled problems, an Active Disturbance Rejection Control (ADRC) is used. The ADRC can observe and compensate the external disturbances without an accurate mathematical model. In works by Sang et al. (2015) and Wu et al. (2018), the trajectory-tracking controller based on ADRC (two channels) is used in the steering system of FWS vehicle. In this paper, a trajectory-tracking controller based on ADRC (four channels) is used to decouple the steering and braking systems of $4 \mathrm{WS}$ vehicle. The controller can track the desired lateral displacement, longitudinal displacement, yaw angle, and roll angle, and minimize the tracking errors between the actual output values and the desired values through steering angle and wheel brake cylinder pressure. Finally, the anti-crosswind, anti-sideslip, and anti-rollover CarSim ${ }^{\circledR}$ simulations verify the effectiveness of the controller.

The rest of this paper is organized as follows. First, Section 1 describes a conversion method between the target trajectory and the initial input of $4 \mathrm{WS}$ autonomous vehicle. Then, in Section 2, a trajectory-tracking controller based on ADRC (four channels) is designed. Furthermore, the anti-crosswind, anti-sideslip, and anti-rollover CarSim ${ }^{\circledR}$ simulations are implemented in Section 3. Finally, the last section presents the conclusions of the work.

\section{Conversion between the target trajectory and the initial input of $4 \mathrm{WS}$ autonomous vehicle}

\subsection{Target trajectory}

Taking the restrictions of the travel anti-clockwise and the second quadrant as an example, the circular bend is a right angled circular bend (single circle center), and its corner angle $\alpha$ is $90^{\circ}$. For detailed trajectory planning process, see research by Liu et al. (2020). The circular bend with right angle is shown in Figure 1. The polar coordinate equation for the desired circular bend is shown as follows:

$$
\left\{\begin{array}{l}
X_{d}=X_{0}+R \cdot \cos (\theta) ; \\
Y_{d}=Y_{0}+R \cdot \sin (\theta),
\end{array}\right.
$$

where: $t$ is the driving time [s]; $R$ is the turning radi- 


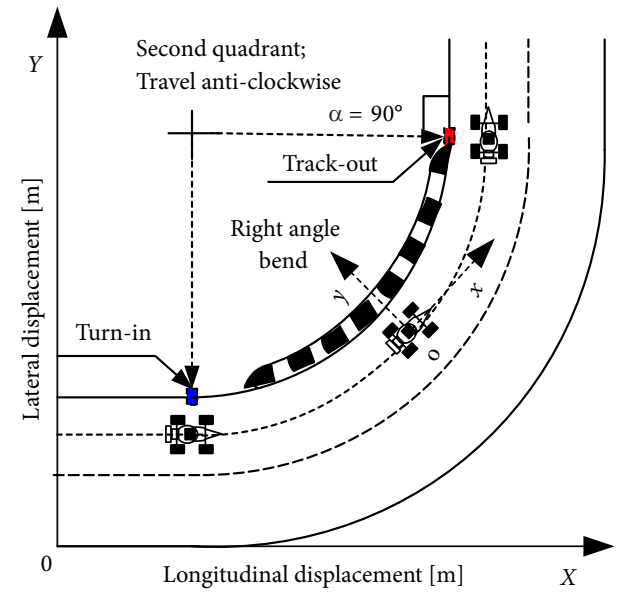

Figure 1. Circular bend with right angle (single circle center)

us [m]; $\theta$ is the radian value corresponding to time $t[\mathrm{rad}]$; $\theta=-\frac{\pi}{2}+\frac{u_{c} \cdot t}{R} ; u_{c}$ represents the longitudinal speed based on vehicle coordinate system; $\left(X_{0}, Y_{0}\right)$ is the circle center coordinate; $Y_{d}$ is the desired lateral displacement based on a ground inertial coordinate system; $X_{d}$ is the desired longitudinal displacement based on a ground inertial coordinate system; the turning radius $R$ is $37.5 \mathrm{~m}$; the circle center coordinate is $\left(X_{0}, Y_{0}\right)=(262.5,37.5)$; the initial coordinate of the autonomous vehicle is $(0,0)$; the ending coordinate of the autonomous vehicle is $(300,300)$.

\subsection{Conversion between the target trajectory and the desired yaw rate}

Considering the conversion relationship between the vehicle coordinate system and the ground inertial coordinate system, after the derivative of the function $X_{d}$ with respect to $X_{d}$, the function of the desired yaw angle $\Omega_{d}$ with respect to $X_{d}$ is shown as follows:

$$
\Omega_{d}\left(X_{d}\right)=\frac{180 \cdot \arctan \left(Y_{d}^{\prime}\left(X_{d}\right)\right)}{\pi} .
$$

Then, the function of the $\Omega_{d}$ with respect to $X_{d}$ is transformed into the function of the $\Omega_{d}$ with respect to $t$. After the derivative of the function $\Omega_{d}$ with respect to $t$, the function of the desired yaw rate $r_{d}$ with respect to $t$ is shown as follows:

$$
r_{d}(t)=\frac{\pi \cdot \Omega_{d}^{\prime}(t)}{180} .
$$

\subsection{Conversion between the desired yaw rate and the initial input of $4 \mathrm{WS}$ autonomous vehicle}

From the perspective of vehicle dynamics, the transfer function from steering wheel angle to yaw rate under transient-state conditions is an approximate second-order lag system response (Cao et al. 2013). To simplify the calculation in the conversion of the desired yaw rate and the desired steering wheel angle, the desired steering wheel angle $\delta_{s w}$ is described as follows:

$$
\delta_{s w}=\frac{r_{d}}{G_{r d}},
$$

where: $G_{r d}$ is the desired steering sensitivity coefficient (desired yaw rate/desired steering wheel angle), $G_{r d}=\frac{u_{c}}{i_{0} \cdot l+i_{0} \cdot l \cdot K \cdot u_{c}^{2}} ; K$ is the stability factor, $K=$ $\frac{m \cdot\left(b \cdot C_{a r}-a \cdot C_{a f}\right)}{l^{2} \cdot C_{a f} \cdot C_{a r}}$.

Finally, the yaw rate and sideslip angle responses of the 4WS autonomous vehicle in this paper are set to a firstorder lag response (Tajima et al. 1999). Combined with the system dynamics model of the 4WS autonomous vehicle (Amdouni et al. 2013), the initial inputs of the 4WS autonomous vehicle are shown as follows:

$$
\begin{aligned}
& \left\{\begin{array}{l}
\frac{\delta_{f d}(s)}{\delta_{s w}(s)}=e_{1} ; \\
\frac{\delta_{r d}(s)}{\delta_{s w}(s)}=e_{2} ;
\end{array}\right. \\
& e_{1}=\frac{m \cdot b \cdot u_{c} \cdot s+l \cdot C_{a f}}{l \cdot C_{a f}} \cdot \frac{G_{\beta d}}{1+T_{\beta} \cdot s}+ \\
& \frac{I_{z} \cdot s+m \cdot b \cdot u_{c}+\frac{l \cdot a \cdot C_{a f}}{u_{c}}}{l \cdot C_{a f}} \cdot \frac{G_{r d}}{1+T_{r} \cdot s} ; \\
& e_{2}=\frac{m \cdot a \cdot u_{c} \cdot s+l \cdot C_{a r}}{l \cdot C_{a r}} \cdot \frac{G_{\beta d}}{1+T_{\beta} \cdot s}- \\
& \frac{I_{z} \cdot s-m \cdot a \cdot u_{c}+\frac{l \cdot b \cdot C_{a r}}{u_{c}}}{l \cdot C_{a r}} \cdot \frac{G_{r d}}{1+T_{r} \cdot s},
\end{aligned}
$$

where: $s$ is the Laplace operator; $\delta_{f d}, \delta_{r d}$ represent the desired front- and rear-wheel steering angles of the 4WS autonomous vehicle, respectively; $T_{r}=\frac{1}{\sqrt{\frac{l^{2} \cdot C_{a f} \cdot C_{a r} \cdot\left(1+K \cdot u_{c}^{2}\right)}{u_{c}^{2} \cdot m \cdot I_{z}}}}$.

\section{Trajectory-tracking controller based on ADRC}

Due to some factors such as tire nonlinearity, load transfer, road adhesion, and crosswind, autonomous vehicles will experience run-off, sideslip or rollover in path tracking. To avoid these problems, ignoring the effects of suspension system, road roughness, and air resistance, an ADRC controller capable of static decoupling steering and braking systems was used to track the desired yaw angle, lateral displacement, and roll angle and minimize the tracking errors between the actual values and the desired values, thus achieving effective anti-crosswind, anti-sideslip, and anti-rollover in trajectory-tracking. 


\subsection{Trajectory-tracking controller based on ADRC (three channels)}

Considering the longitudinal, lateral and yaw movements of autonomous vehicles in trajectory-tracking, we designed a three channel ADRC trajectory-tracking controller, where the three channels represent the control of the longitudinal, lateral and yaw movements for autonomous vehicles, respectively. It can not only compensate the errors of actual and desired longitudinal and lateral displacements by the steering angle but also compensate for the errors of actual and desired yaw angles by yaw moment. The state equations of the second-order linear control systems for the three channels are described as:

$$
\left\{\begin{array}{l}
\dot{x}_{1}=x_{2} ; \\
\dot{x}_{2}=f_{1}(t)+w_{1}(t)+b_{1} \cdot U_{f}+b_{2} \cdot u_{1} ; \\
\dot{x}_{3}=x_{4} ; \\
\dot{x}_{4}=f_{2}(t)+w_{2}(t)+b_{3} \cdot U_{f}+b_{4} \cdot u_{1}+b_{4} \cdot u_{2} ; \\
\dot{x}_{5}=x_{6} ; \\
\dot{x}_{6}=f_{3}(t)+w_{3}(t)+b_{5} \cdot U_{f}+b_{6} \cdot u_{1}+b_{6} \cdot u_{2}+b_{7} \cdot u_{3} ; \\
y_{1}=x_{1} ; \\
y_{2}=x_{3} ; \\
y_{3}=x_{5} ; \\
f_{1}(t)=\frac{b \cdot C_{a r}-a \cdot C_{a f}}{m \cdot u_{c}} r-\frac{C_{a f}+C_{a r}}{m \cdot u_{c}} v_{y} ; \\
f_{2}(t)=\frac{C_{l f} \cdot s_{f}}{m}+\frac{C_{l r} \cdot s_{r}}{m} ; \\
f_{3}(t)=\frac{b \cdot C_{a r}-a \cdot C_{a f}}{I_{z} \cdot u_{c}} \cdot v_{y}-\frac{a^{2} \cdot C_{a f}+b^{2} \cdot C_{a r}}{I_{z} \cdot u_{c}} \cdot r ; \\
b_{1}=\left(\frac{C_{a f}+C_{l f} \cdot s_{f}}{m}, \frac{C_{a r}+C_{l r} \cdot s_{r}}{m}\right) ; \\
b_{2}=\frac{C_{a f}+C_{l f} \cdot s_{f}}{m} ; \\
b_{3}=\left(\frac{C_{a f} \cdot\left(v_{y}+a \cdot r\right)}{m \cdot u_{c}}, \frac{C_{a r} \cdot\left(v_{y}-b \cdot r\right)}{m \cdot u_{c}}\right) ; \\
b_{4}=\frac{C_{a f} \cdot\left(v_{y}+a r\right)}{m \cdot u_{c}} ; \\
b_{5}=\left(\frac{a \cdot C_{a f}+a \cdot C_{l f} \cdot s_{f}}{I_{z}},-\frac{b \cdot C_{a r}+b \cdot C_{l r} \cdot s_{r}}{I_{z}}\right) ; \\
b_{6}=\frac{a \cdot C_{a f}+a \cdot C_{l f} \cdot s_{f}}{I_{z}} ;
\end{array}\right.
$$

where: $r$ is the yaw rate based on vehicle coordinate system; $y_{1}, y_{2}, y_{3}$ are the outputs of three channels, that is, $y_{1}=Y, y_{2}=X, y_{3}=\Omega ; u_{1}$ (FWS angle), $u_{2}$ (FWS angle), $u_{3}$ (yaw moment) are the actual feedback controls of three channels; $U_{f}=\left(\frac{\pi \cdot \delta_{f d}}{180}, \frac{\pi \cdot \delta_{r d}}{180}\right)^{T} ; w_{1}, w_{2}, w_{3}$ are the internal and external disturbances of three channels. Setting $y_{1}^{*}=Y_{d}, y_{2}^{*}=X_{d}, y_{3}^{*}=\Omega_{d}$, the ADRC algorithms of three channels are shown as follows:

$$
\begin{aligned}
& \left\{\begin{array}{l}
f h=-r_{0}^{2} \cdot\left(v_{11}-y_{1}^{*}\right)-2 \cdot r_{0} \cdot v_{12} \\
\dot{v}_{11}=v_{12} ; \\
\dot{v}_{12}=f h ; \\
e=z_{11}-y_{1} ; \\
f e=f a l(e, 0.5, h) ; \\
f e_{1}=\text { fal }(e, 0.25, h) ; \\
\dot{z}_{11}=z_{12}-\beta_{01} \cdot e ; \\
\dot{z}_{12}=z_{13}-\beta_{02} \cdot f e+U_{1} ; \\
\dot{z}_{13}=-\beta_{03} \cdot f e_{1} ; \\
e_{1}=v_{11}-z_{11} ; \\
e_{2}=v_{12}-z_{12} ; \\
u_{0}=- \text { fhan }\left(e_{1}, c \cdot e_{2}, r_{1}, h_{1}\right) ; \\
U_{1}=u_{0}-z_{13} ;
\end{array}\right. \\
& \left\{\begin{array}{l}
f h=-r_{0}^{2} \cdot\left(v_{21}-y_{2}^{*}\right)-2 \cdot r_{0} \cdot v_{22} ; \\
\dot{v}_{21}=v_{22} ;
\end{array}\right. \\
& \dot{v}_{22}=f h \text {; } \\
& e=z_{21}-y_{2} \\
& f e=f a l(e, 0.5, h) \text {; } \\
& f e_{1}=\mathrm{fal}(e, 0.25, h) \text {; } \\
& \dot{z}_{21}=z_{22}-\beta_{01} \cdot e \text {; } \\
& \dot{z}_{22}=z_{23}-\beta_{02} \cdot f e+U_{2} \text {; } \\
& \dot{z}_{23}=-\beta_{03} \cdot f e_{1} \text {; } \\
& e_{1}=v_{21}-z_{21} \text {; } \\
& e_{2}=v_{22}-z_{22} \text {; } \\
& u_{0}=- \text { fhan }\left(e_{1}, c \cdot e_{2}, r_{1}, h_{1}\right) \text {; } \\
& U_{2}=u_{0}-z_{23} \text {; } \\
& \left\{\begin{array}{l}
f h=-r_{0}^{2} \cdot\left(v_{31}-y_{3}^{*}\right)-2 \cdot r_{0} \cdot v_{32} ; \\
\dot{v}_{31}=v_{32} ;
\end{array}\right. \\
& \dot{v}_{32}=f h \\
& e=z_{31}-y_{3} \text {; } \\
& f e=f a l(e, 0.5, h) \text {; } \\
& f e_{1}=\mathrm{fal}(e, 0.25, h) \text {; } \\
& \dot{z}_{31}=z_{32}-\beta_{01} \cdot e \text {; } \\
& \dot{z}_{32}=z_{33}-\beta_{02} \cdot f e+U_{3} \text {; } \\
& \dot{z}_{33}=-\beta_{03} \cdot f e_{1} \text {; } \\
& e_{1}=v_{31}-z_{31} \text {; } \\
& e_{2}=v_{32}-z_{32} \text {; } \\
& u_{0}=- \text { fhan }\left(e_{1}, c e_{2}, r_{1}, h_{1}\right) \text {; } \\
& U_{3}=u_{0}-z_{33} \text {, }
\end{aligned}
$$

where $U_{1}, U_{2}, U_{3}$ are the virtual feedback controls; $h, h_{1}$ are the integral steps, $h=0.001 ; h_{1}=0.1 ; r_{0}, r_{1}$ are the tracking speed factors, $r_{0}=20, r_{1}=5 ; c=1 ; \beta_{01}, \beta_{02}, \beta_{03}$ are the ESO parameters, $\beta_{01}=100, \beta_{02}=300, \beta_{03}=1000$; 
$\mathrm{fal}(-)$ is a nonlinear function; fhan(-) is a tracking differential function (Han 2009).

The ADRC controller consists of three modules: tracking differentiator, Extended State Observer (ESO), and state error compensation law (Xia et al. 2016). First, the tracking differentiator is to plan the desired target conversion and provide a valid error signal. Its tracking goals are: $v_{11} \rightarrow Y_{d}, v_{12} \rightarrow \dot{Y}_{d}, v_{21} \rightarrow X_{d}, v_{22} \rightarrow \dot{X}_{d}, v_{31} \rightarrow \Omega_{d}$, and $v_{32} \rightarrow \dot{\Omega}_{d}$. Second, the ESO is to estimate the state parameters and disturbances of the control system. Its target values are: $z_{11} \rightarrow Y, z_{12} \rightarrow \dot{Y}, z_{13} \rightarrow f_{1}(t)+w_{1}(t)+b_{1} \cdot U_{f}$, $z_{21} \rightarrow X, z_{22} \rightarrow \dot{X}, z_{23} \rightarrow f_{2}(t)+w_{2}(t)+b_{3} \cdot U_{f}, z_{31} \rightarrow \Omega$, $z_{32} \rightarrow \dot{\Omega}$, and $z_{33} \rightarrow f_{3}(t)+w_{3}(t)+b_{5} \cdot U_{f}$. Third, the state errors of the lateral displacement, longitudinal displacement, and yaw angle are compensated dynamically by the state error compensation laws in Equations (7)-(9). Finally, through static decoupling of virtual feedback controls $U_{1}, U_{2}$, and $U_{3}$, the actual feedback controls of three channels are expressed as:

$$
\left[\begin{array}{l}
u_{1} \\
u_{2} \\
u_{3}
\end{array}\right]=B_{1}^{-1} \cdot\left[\begin{array}{l}
U_{1} \\
U_{2} \\
U_{3}
\end{array}\right]=\left[\begin{array}{ccc}
b_{2} & 0 & 0 \\
b_{4} & b_{4} & 0 \\
b_{6} & b_{6} & b_{7}
\end{array}\right]^{-1} \cdot\left[\begin{array}{c}
U_{1} \\
U_{2} \\
U_{3}
\end{array}\right]
$$

\subsection{Trajectory-tracking controller based on ADRC (four channels)}

To realize the anti-rollover of autonomous driving vehicles, an ADRC trajectory-tracking controller (four channels) considering rollover is designed. The controller introduces a fourth channel to control the roll motion, thereby interfering with the roll motion of the vehicle. In addition to tracking the desired lateral displacement, longitudinal displacement, and yaw angle, the controller can also prevent rollover by tracking the desired roll angle $\varphi_{d}$. Since the fourth channel in this controller is exactly opposite to the control rules of the first three channels (see Table 1 of the control rules for details), the anti-rollover function of the fourth channel comes at the expense of the path-tracking performance of the vehicle. To reduce the trajectory-tracking errors as much as possible while achieving rollover prevention, the anti-rollover control method is activated only when the lateral acceleration is greater than the rollover threshold and is stopped when the actual lateral acceleration is less than the rollover threshold (Solmaz et al. 2007; Larish et al. 2013). The rollover threshold of the autonomous vehicle is set to

$$
a_{y \lim }=\frac{T_{w} \cdot g}{2 \cdot h_{a}}+\phi \cdot g
$$

where: $\phi$ is the road slope angle. The desired roll angle $\varphi_{d}$ is described as (Piyabongkarn et al. 2004):

$$
\varphi_{d}=\arctan \left(\frac{u_{c} \cdot r_{d}}{g}\right) \text {. }
$$

The Load Transfer Rate (LTR) is selected as the rollover index to determine the degree of rollover occurrence
(Braghin et al. 2008). It indicates the vertical LTR of the left and right wheels. Its calculation formula is shown as follows:

$$
L T R=\frac{F_{z r}-F_{z l}}{F_{z r}+F_{z l}}
$$

where: $F_{z l}$ and $F_{z r}$ are the dynamic vertical loads of the left and right wheels, respectively. The absolute value of LTR is between 0 and 1 . The greater the absolute value, the greater the risk of rollover. When the absolute value is 1 , it indicates that the vehicle has rollover. The state equation of the second-order linear control systems for the fourth channel is described as:

$$
\left\{\begin{array}{l}
\dot{x}_{7}=x_{8} ; \\
\dot{x}_{8}=f_{4}(t)+w_{4}(t)+b_{8} \cdot U_{f}+b_{9} \cdot u_{1}+b_{9} \cdot u_{2}+b_{9} \cdot u_{4} ; \\
y_{4}=x_{7} ; \\
f_{4}(t)=\frac{m \cdot a_{y}}{m_{s} \cdot h_{s}}-\frac{b \cdot C_{a r}-a \cdot C_{a f}}{m_{s} \cdot h_{s} \cdot u_{c}} r+\frac{C_{a f}+C_{a r}}{m_{s} \cdot h_{s} \cdot u_{c}} \cdot v_{y} ; \\
b_{8}=\left(\frac{-C_{a f}}{m_{s} \cdot h_{s}}, \frac{-C_{a r}}{m_{s} \cdot h_{s}}\right) ; \\
b_{9}=\frac{-C_{a f}}{m_{s} \cdot h_{s}},
\end{array}\right.
$$

where: $a_{y}$ is the lateral acceleration based on vehicle coordinate system; $y_{4}=\varphi$ is the output of the fourth channel; $u_{4}$ (FWS angle) is actual feed-back control of the fourth channel; $w_{4}$ is the internal and external disturbances of the fourth channel. Setting $y_{4}^{*}=\varphi_{d}$, the ADRC algorithm of the fourth channel is shown as follows:

$$
\left\{\begin{array}{l}
f h=-r_{0}^{2} \cdot\left(v_{41}-y_{4}^{*}\right)-2 \cdot r_{0} \cdot v_{42} ; \\
\dot{v}_{41}=v_{42} \\
\dot{v}_{42}=f h ; \\
e=z_{41}-y_{4} ; \\
f e=\operatorname{fal}(e, 0.5, h) ; \\
f e_{1}=\operatorname{fal}(e, 0.25, h) ; \\
\dot{z}_{41}=z_{42}-\beta_{01} \cdot e ; \\
\dot{z}_{42}=z_{43}-\beta_{02} \cdot f e+U_{4} ; \\
\dot{z}_{43}=-\beta_{03} \cdot f e_{1} ; \\
e_{1}=v_{41}-z_{41} ; \\
e_{2}=v_{42}-z_{42} ; \\
u_{0}=- \text { fhan }\left(e_{1}, c \cdot e_{2}, r_{1}, h_{1}\right) ; \\
U_{4}=u_{0}-z_{43},
\end{array}\right.
$$

where: $U_{4}$ is the virtual feedback control. The tracking goals of the tracking differentiator are: $v_{41} \rightarrow \varphi_{d}$, $v_{42} \rightarrow \dot{\varphi}_{d}$; and the target values of the ESO are: $z_{41} \rightarrow \varphi$, $z_{42} \rightarrow \dot{\varphi}, z_{43} \rightarrow f_{4}(t)+w_{4}(t)+b_{8} \cdot U_{f}$. The state error of the roll angle is compensated dynamically by the state error compensation law in Equation (15). Finally, through static decoupling of virtual feedback controls $U_{1}, U_{2}, U_{3}$, and $U_{4}$, the actual feedback controls of four channels are expressed as: 


$$
\left[\begin{array}{l}
u_{1} \\
u_{2} \\
u_{3} \\
u_{4}
\end{array}\right]=B_{2}{ }^{-1} \cdot\left[\begin{array}{l}
U_{1} \\
U_{2} \\
U_{3} \\
U_{4}
\end{array}\right]=\left[\begin{array}{cccc}
b_{2} & 0 & 0 & 0 \\
b_{4} & b_{4} & 0 & 0 \\
b_{6} & b_{6} & b_{7} & 0 \\
b_{9} & b_{9} & 0 & b_{9}
\end{array}\right]^{-1} \cdot\left[\begin{array}{c}
U_{1} \\
U_{2} \\
U_{3} \\
U_{4}
\end{array}\right] .
$$

When the lateral acceleration of the autonomous vehicle in trajectory-tracking is greater than the rollover threshold, the actual feedback controls of the controller are $u_{1}, u_{2}, u_{3}$, and $u_{4}$. When the lateral acceleration is less than the rollover threshold, the actual feedback controls of the controller are only $u_{1}, u_{2}$, and $u_{3}$.

Finally, the $u_{1}$ (FWS angle [rad]), $u_{2}$ (FWS angle $[\mathrm{rad}]), u_{3}$ (yaw moment $[\mathrm{N} \cdot \mathrm{m}]$ ), and $u_{4}$ (FWS angle [rad]) are converted to $u_{1}^{*}$ (FWS angle $\left.\left[{ }^{\circ}\right]\right), u_{2}^{*}$ (FWS angle $\left[{ }^{\circ}\right]$ ), $u_{3}^{*}$ (wheel brake cylinder pressure [MPa]), and $u_{4}^{*}$ (FWS angle $\left.\left[{ }^{\circ}\right]\right)$, respectively. The feedback inputs of the autonomous vehicle are shown as follows:

$$
\left\{\begin{array}{l}
u_{1}^{*}=\frac{180}{\pi} \cdot u_{1} ; \\
u_{2}^{*}=\frac{2 \cdot R_{w}}{T_{w} \cdot \psi} \cdot u_{2} ; \\
u_{3}^{*}=\frac{180}{\pi} \cdot u_{3} ; \\
u_{4}^{*}=\frac{180}{\pi} \cdot u_{4} .
\end{array}\right.
$$

To prevent rear-wheel lockup in trajectory-tracking, for the $\mathrm{CarSim}^{\circledast}$ brake system, the brake torque / wheel brake cylinder pressure values of the left and right frontwheels were set to $\psi=300 \mathrm{~N} \cdot \mathrm{m} / \mathrm{MPa}$, and the brake torque / wheel brake cylinder pressure values of the left and right rear-wheels were set to $\psi=150 \mathrm{~N} \cdot \mathrm{m} / \mathrm{MPa}$. The total control algorithm flow chart of the trajectory-tracking controller (four channels) is shown in Figure 2. The general control rules of the controller are shown in Table 1, where: LF - Left Front and LR - Left Rear wheels, respectively, while RF - Right Front and RR - Right Rear wheels, respectively.

\section{CarSim ${ }^{\circledR}$ simulations}

\subsection{Four different trajectory-tracking controllers}

Four different trajectory-tracking controllers for autonomous vehicles in the following simulations are shown as follows:

"» the trajectory-tracking controller based on an optimal preview is defined as controller 1 , which is a trajectory-tracking controller for FWS vehicle. The red vehicle in the following simulations represents controller 1;

"» the trajectory-tracking controller based on ADRC (two channels) is defined as controller 2, which is a

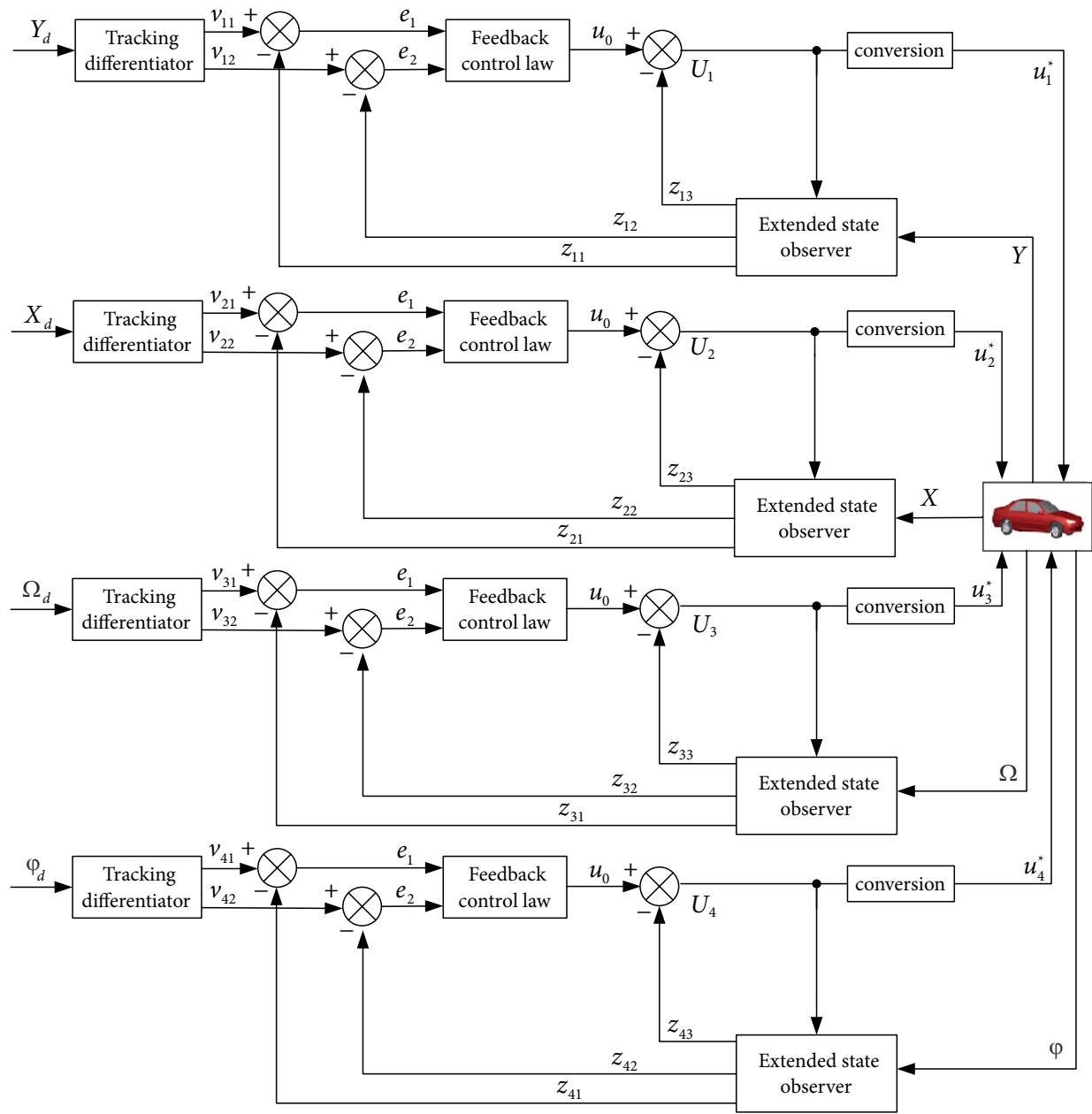

Figure 2. Total control algorithm flow chart of the trajectory-tracking controller (four channels) 
Table 1. The general control rules of the trajectory-tracking controller (four channels)

\begin{tabular}{|c|c|c|}
\hline $\begin{array}{c}\text { Decision } \\
\text { condition }\end{array}$ & $\begin{array}{c}\text { FWS angle } \\
\text { (positive and negative) }\end{array}$ & $\begin{array}{c}\text { Wheel brake cylinder } \\
\text { pressure (brake wheel) }\end{array}$ \\
\hline$Y-Y_{d}>0$ & $u_{1}^{*}<0$ (right turn) & - \\
\hline$Y-Y_{d}<0$ & $u_{1}^{*}>0$ (left turn) & - \\
\hline$X-X_{d}>0$ & $u_{2}^{*}>0$ (left turn) & - \\
\hline$X-X_{d}<0$ & $u_{2}^{*}<0$ (right turn) & - \\
\hline$\Omega-\Omega_{d}>0$ & - & $u_{3}^{*}$ acts on RF and RR \\
\hline$\Omega-\Omega_{d}<0$ & - & $u_{3}^{*}$ acts on LF and LR \\
\hline$\varphi-\varphi_{d}>0$ & $u_{4}^{*}<0$ (right turn) & - \\
\hline$\varphi-\varphi_{d}<0$ & $u_{4}^{*}>0$ (left turn) & - \\
\hline
\end{tabular}

Note: $\mathrm{CarSim}^{\circledR}$ specifics: steering angle (left turn is positive, right turn is negative); roll angle (left turn is positive, right turn is negative).

trajectory-tracking controller for $4 \mathrm{WS}$ vehicle. The blue vehicle in the following simulations represents controller 2;

"» the trajectory-tracking controller based on ADRC (three channels) is defined as controller 3, which is a trajectory-tracking controller for $4 \mathrm{WS}$ vehicle. The green vehicle in the following simulations represents controller 3;

"»" the trajectory-tracking controller based on ADRC (four channels) is defined as controller 4 , which is a trajectory-tracking controller for 4WS vehicle. The white vehicle in the following simulations represents controller 4 .

Controller 1 based on the optimal preview control had been applied to the trajectory-tracking model of CarSim ${ }^{\circledR}$ software, and its detailed control process is described in research by MacAdam (1981). In addition, the overall block diagrams of controllers 2, 3 and 4 are shown in Figure 3.

A front-drive vehicle model (D-class Sedan) of Car$\mathrm{Sim}^{\circledR}$ was used in the following trajectory-tracking simulations. Some of the main parameters for the vehicle model are shown in Table 2.

\subsection{Anti-crosswind simulation}

When vehicles are driving on the an icy and snowy road (road adhesion coefficient $\mu=0.1 \ldots 0.3$ ), the vehicles are prone to running off due to crosswind interference. We hoped that autonomous vehicles would have good trajectory-tracking performance even under crosswind and snowy road conditions.

A one-way single-lane road was used as an anti-crosswind simulation path, and the width of the lane was $8 \mathrm{~m}$. The $\mu$ of the icy and snowy road was set to 0.2 , and the $\mu$ of the dry asphalt road was 0.85 . The crosswind fans produce $100 \mathrm{~km} / \mathrm{h}$ wind from the right side, as well as the left side. Since the aerodynamic force is applied at the vehicle reference point, the torque around the Centre of Gravity (CG) is produced. The vehicle speed was set to $80 \mathrm{~km} / \mathrm{h}$.

a) $\left(X_{0}, Y_{0}\right)$

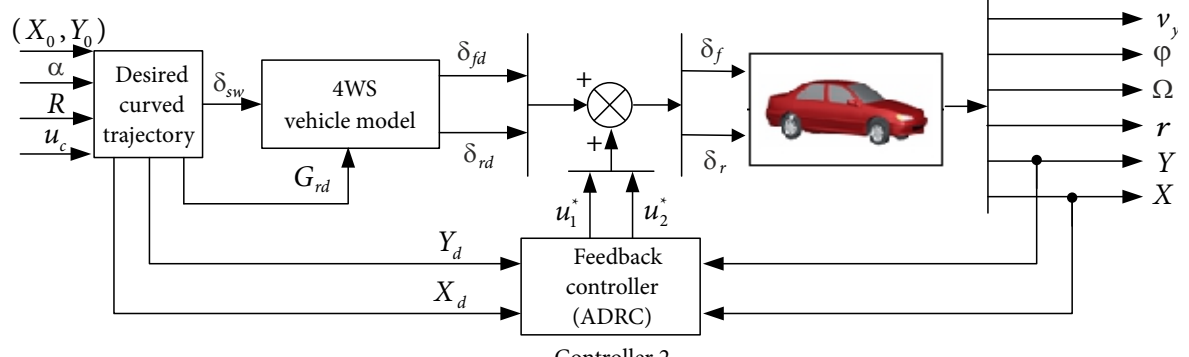

b)

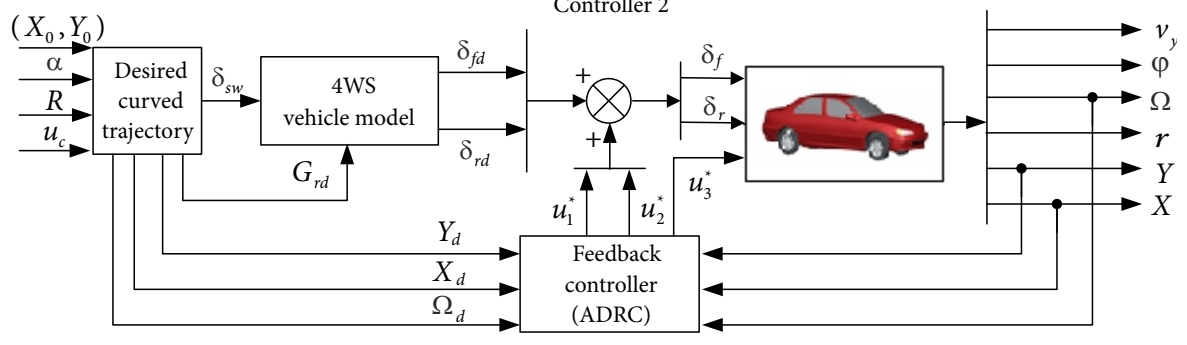

c) $\left(X_{0}, Y_{0}\right)$

Controller 3

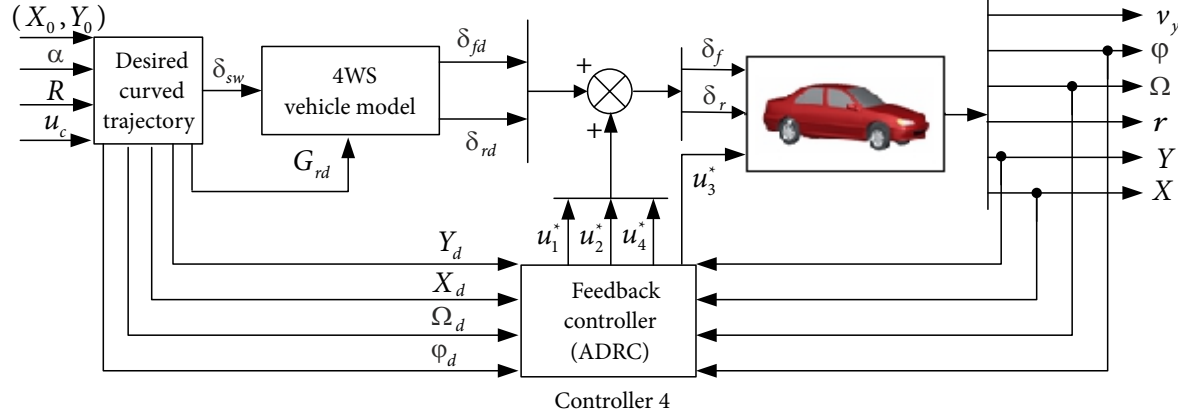

Figure 3. Overall block diagrams: a - controller 2; b - controller 3; c - controller 4 
Table 2. Parameters of a D-class sedan

\begin{tabular}{|l|c|c|c|}
\hline \multicolumn{1}{|c|}{ Model parameter } & Notation & Unit & Value \\
\hline Yaw moment of inertia & $I_{z}$ & $\mathrm{~kg} \cdot \mathrm{m}^{2}$ & 4607.47 \\
\hline Roll moment of inertia & $I_{x}$ & $\mathrm{~kg} \cdot \mathrm{m}^{2}$ & 708.22 \\
\hline Total mass of vehicle & $m$ & $\mathrm{~kg}$ & 1530 \\
\hline Sprung mass of vehicle & $m_{s}$ & $\mathrm{~kg}$ & 1370 \\
\hline $\begin{array}{l}\text { Distances from vehicle CG } \\
\text { to front axle }\end{array}$ & $a$ & $\mathrm{~m}$ & 1.11 \\
\hline $\begin{array}{l}\text { Distances from vehicle CG } \\
\text { to rear axle }\end{array}$ & $b$ & $\mathrm{~m}$ & 1.66622 \\
\hline Track width & $T_{w}$ & $\mathrm{~m}$ & 1.55 \\
\hline Wheel radius & $R_{w}$ & $\mathrm{~m}$ & 0.335 \\
\hline Vehicle wheelbase & $l$ & $\mathrm{~m}$ & 2.77622 \\
\hline $\begin{array}{l}\text { Roll arm distances between } \\
\text { CG to roll center }\end{array}$ & $h_{s}$ & $\mathrm{~m}$ & 0.4 \\
\hline Distances from CG to ground & $h_{a}$ & $\mathrm{~m}$ & 0.54 \\
\hline Vehicle height & $h_{0}$ & $\mathrm{~m}$ & 1.471 \\
\hline Vehicle length & $l_{0}$ & $\mathrm{~m}$ & 4.52 \\
\hline Vehicle width & $w_{0}$ & $\mathrm{~m}$ & 1.8 \\
\hline $\begin{array}{l}\text { Roll stiffness coefficient } \\
\text { of suspension }\end{array}$ & $k_{\varphi}$ & $\mathrm{N} \cdot \mathrm{m} / \mathrm{rad}$ & 55000 \\
\hline $\begin{array}{l}\text { Roll damping coefficient } \\
\text { of suspension }\end{array}$ & $c_{\varphi}$ & $\mathrm{N} \cdot \mathrm{m} \cdot \mathrm{s} / \mathrm{rad}$ & 3500 \\
\hline $\begin{array}{l}\text { Initial transmission ratio } \\
\text { of } \delta_{s w} \text { to } \delta_{f}\end{array}$ & $i_{0}$ & & 23 \\
\hline Front-wheel optimal slip ratio & $s_{f}$ & $\mathrm{~N} / \mathrm{rad}$ & 114220 \\
\hline Rear-wheel optimal slip ratio & $\mathrm{s}_{\mathrm{r}}$ & $C_{l f}$ & 0.2 \\
\hline $\begin{array}{l}\text { Static cornering stiffness } \\
\text { of front axle }\end{array}$ & $C_{a f}$ & $\mathrm{~N} / \mathrm{rad}$ & 195874 \\
\hline $\begin{array}{l}\text { Static cornering stiffness } \\
\text { of rear axle }\end{array}$ & $C_{a r}$ & $\mathrm{~N} / \mathrm{rad}$ & 140574 \\
\hline $\begin{array}{l}\text { Longitudinal stiffness } \\
\text { of front axle }\end{array}$ & $\begin{array}{l}\text { Longitudinal stiffness } \\
\text { of rear axle }\end{array}$ & $\mathrm{rad}$ & 171480 \\
\hline
\end{tabular}

The animation effects for three different vehicles are shown in Figure $4 \mathrm{a}$, where the blue dashed line is the target path, that is, $Y_{d}=0$. The speed and heading of the crosswind are shown in Figure $4 b, 4 c$, the lateral displacements and yaw angles are shown in Figure 4d, 4e, and the steering angles and four brake cylinder pressures are shown in Figure 5.

Figure 4 shows that the red and blue vehicles experienced run-off under the influence of the crosswind, but the green car did not. As shown is Figure 5e, 5f, when the green vehicle was driving at the first crosswind fans (the time was about between 1 and $3 \mathrm{~s}$ ), to prevent the vehicle from driving to the right, $u_{1}^{*}>0$ (left turn), $u_{2}^{*}>0$ (left turn), and $u_{3}^{*}$ acted on LF and LR; when the green vehicle was driving at the second crosswind fans (the time was about between 4 and $6 \mathrm{~s}$ ), to suppress the tendency of the vehicle to travel to the left, $u_{1}^{*}<0$ (right turn), $u_{2}^{*}<0$ (right turn), and $u_{3}^{*}$ acted on RF and RR.

\subsection{Anti-sideslip simulation}

When it comes to steering on a wet and slippery road (the road adhesion coefficient $\mu=0.5 \ldots 0.6$ ), vehicles (front- drive) are often found to visibly push ahead or rush out of the runway (under-steer). We hoped that autonomous vehicles would effectively reduce sideslip in trajectorytracking, especially under a small turning radius and wet curved roads.

A one-way four-lane road was used as an anti-sideslip simulation path, and the width of each lane was $3.5 \mathrm{~m}$. The road adhesion coefficient $\mu$ of the road was set to 0.55 . The detailed road conditions are shown in Figure 1 and meet the SAE Standard J3087_201710 (Lee 1996). The vehicle speed was set to $50 \mathrm{~km} / \mathrm{h}$. The animation effects, lateral displacements, and yaw angles for three different vehicles are shown in Figure 6. The steering angles and four brake cylinder pressures for three different vehicles are shown in Figure 7. Phase trajectories on the sideslip angle, phase trajectories on the roll angle, lateral accelerations, and lateral forces for three different vehicles are shown in Figure 8. The $e$ in Figure 8a represents the deviation of the actual sideslip angle from the expected value. The $e$ in Figure 8b represents the deviation of the actual roll angle from the expected value.

As can be seen from Figure 6, the three vehicles all have sideslip of front-wheel (under-steer) in trajectorytracking under this road condition. For the green vehicle, the maximum deviation between the actual lateral displacement and the desired value is $1.5 \mathrm{~m}$. For the blue vehicle, it is $3.5 \mathrm{~m}$. For the red vehicle, it exceeds $6 \mathrm{~m}$, which directly causes the vehicle to lose control and rush out of the runway.

When the vehicle enters the corner, in order to prevent the vehicle from slipping to the right due to insufficient tire force and inertia, $u_{1}^{*}>0$ (left turn), $u_{2}^{*}>0$ (left turn), and $u_{3}^{*}$ act on LF and LR, thereby preventing the vehicle from driving to the right. When the vehicle drives out of the corner, in order to prevent the vehicle from slipping to the left due to insufficient tire force and inertia, $u_{1}^{*}<0$ (right turn), $u_{2}^{*}<0$ (right turn), and $u_{3}^{*}$ act on RF and $\mathrm{RR}$, thereby preventing the vehicle from driving to the left.

As shown is Figure 7e, 7f, the rear-wheels of the green vehicle are steered in the opposite direction to the front ones when entering the corner, and its rear-wheels are steered in the same direction as the front ones when driving out of the corner, thus realizing the characteristics of "small turning radius into the bend, stable out of the bend" (Sirou, Galtier 1991).

Figure $8 \mathrm{a}, 8 \mathrm{~b}$ shows that the phase trajectories on the sideslip angle and roll angle for the red vehicle are not closed, which indicates that the control system is unstable. The enclosure areas of the green vehicle are the smallest, which indicates that controller 3 is stable and has high control precision. Figure $8 \mathrm{c}$ shows that the actual lateral acceleration value of the green vehicle is closer to the desired value. Figure $8 \mathrm{~d}-8 \mathrm{f}$ indicates that controller 3 can produce greater tire lateral forces, thus improving the safety and stability of the vehicle in curved trajectorytracking, even on curved roads with a small turning radius and slippery surface. However, for the high CG of 
a)

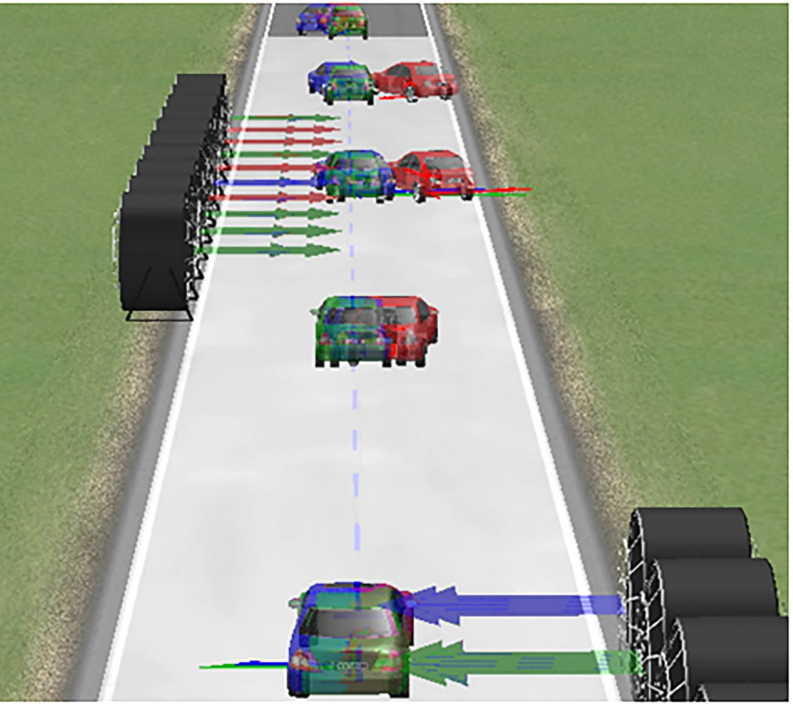

b)

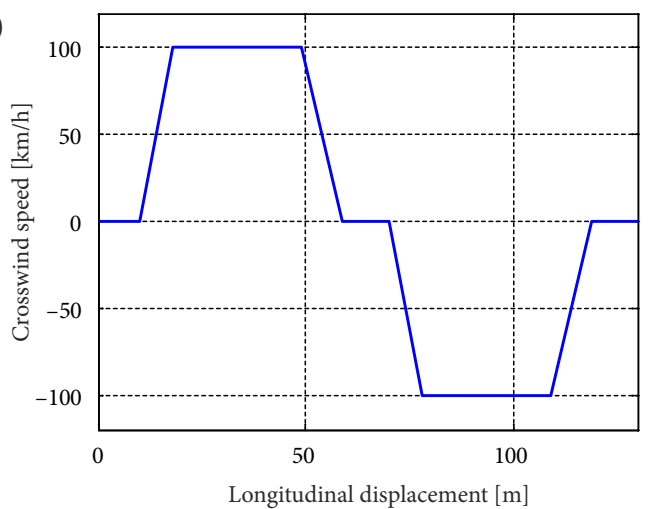

d)

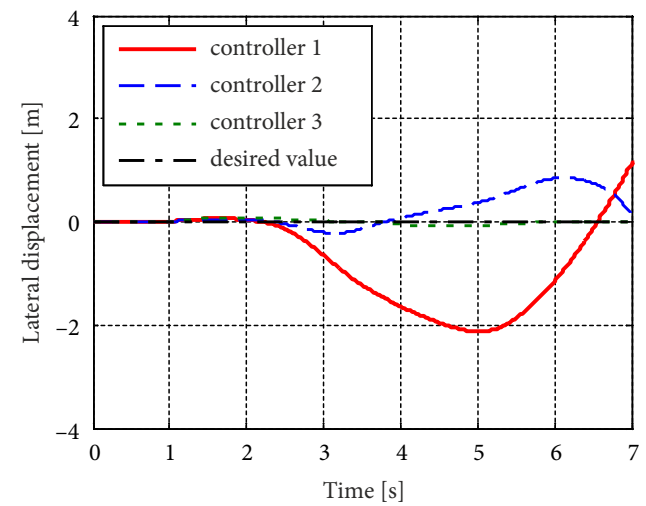

c)

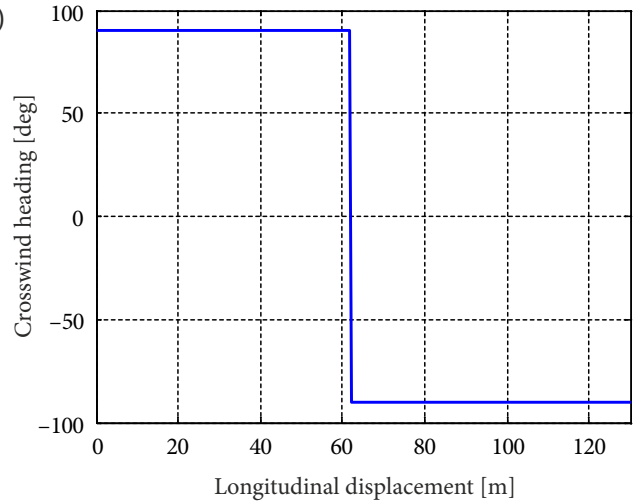

e)

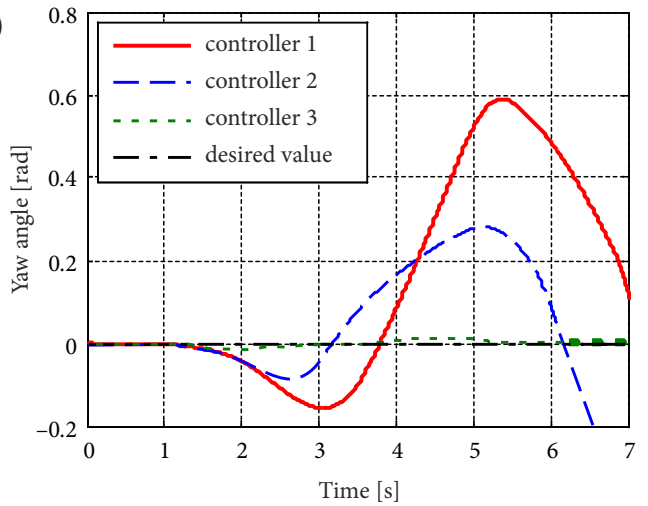

Figure 4. Simulation results in the anti-crosswind simulation: $\mathrm{a}$ - animation effect; $\mathrm{b}$ - crosswind speed; $\mathrm{c}$ - crosswind heading; $\mathrm{d}$ - lateral displacement; e - yaw angle

Sports Utility Vehicle (SUV) at high-speeds, controller 3 may cause the vehicle to roll over prematurely in curved trajectory-tracking, as detailed in the next section.

\subsection{WS anti-rollover simulation}

Current Electronic Stability Control (ESC) is not only able to reduce vehicle under-steer and over-steer by applying a braking force but also prevents rollover by reducing the vehicle speed (Guo et al. 2010). However, in the anti-rollo- ver simulation, we hoped that autonomous vehicles would effectively prevent rollover in trajectory-tracking without losing vehicle speed as much as possible.

For the simulation vehicle (D-class sedan) of this paper, the rollover threshold of the vehicle was $a_{y \lim } \approx 14.06 \mathrm{~m} / \mathrm{s}^{2}$. However, due to the road adhesion condition and maximum tire lateral force limit, the maximum lateral acceleration $a_{y \max }\left(a_{y \max } \leq \mu \cdot g\right)$ of the vehicle was much smaller than the rollover threshold $a_{y \mathrm{lim}}$. Thus, no matter how fast it was going, the vehicle could not roll over. 
a)

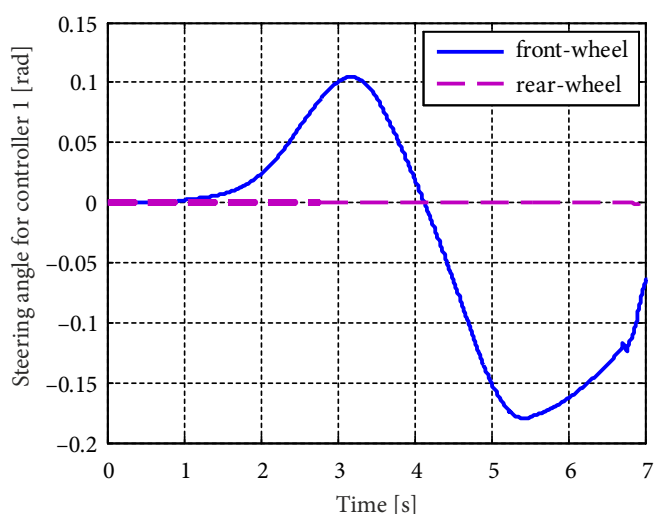

c)

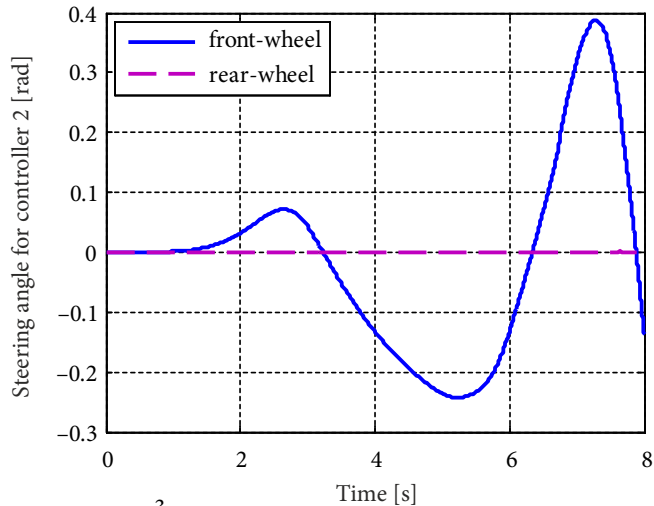

e)

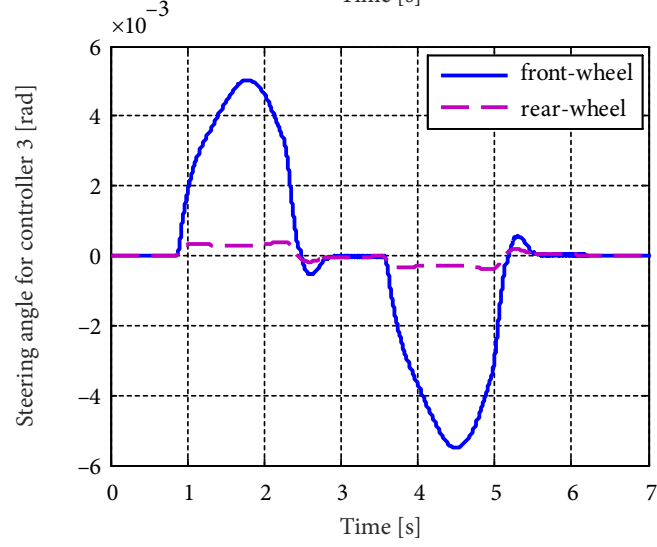

b)

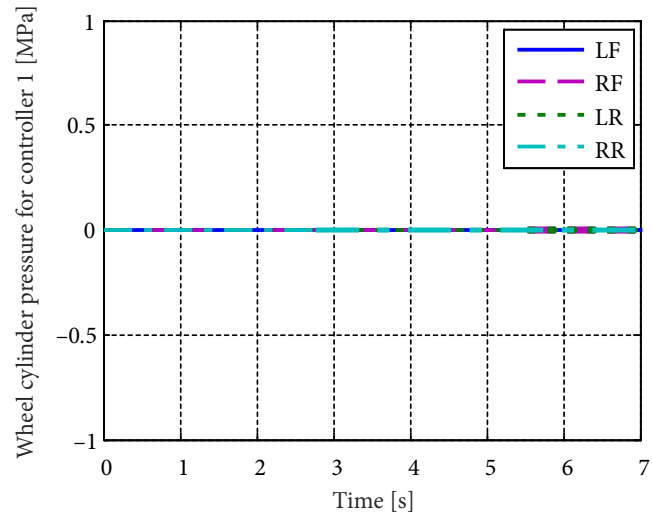

d)

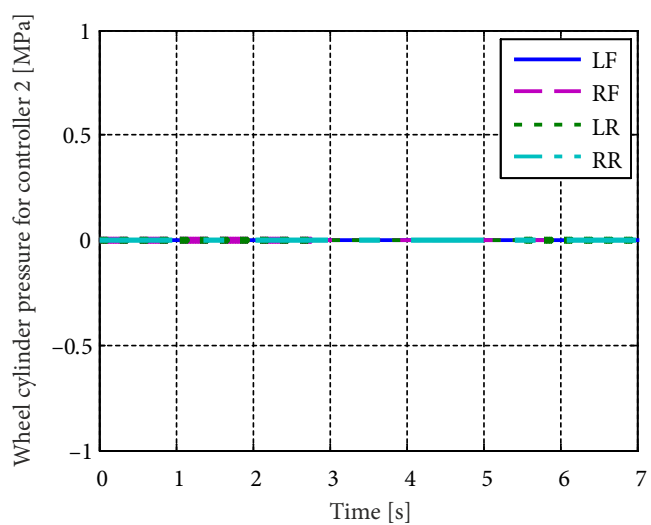

f)

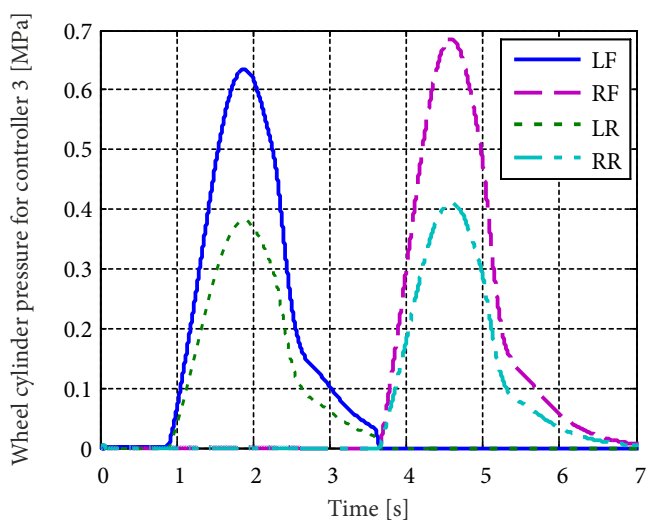

Figure 5. The steering angles and four brake cylinder pressures in the anti-crosswind simulation: $\mathrm{a}, \mathrm{b}$ - red vehicle; $\mathrm{c}, \mathrm{d}$ - blue vehicle; e, $\mathrm{f}$ - green vehicle

To meet the requirements of the anti-rollover simulation, the vehicle model was adjusted to an SUV model, where $h_{a}$ was adjusted from $0.54 \mathrm{~m}$ to $0.82 \mathrm{~m}, h_{0}$ was adjusted from $1.471 \mathrm{~m}$ to $1.679 \mathrm{~m}$, and other vehicle parameters remained unchanged. Then, the rollover threshold of the SUV became $a_{y^{-}} \approx 9.26 \mathrm{~m} / \mathrm{s}^{2}$, thus meeting the simulation requirements.

The road conditions of the anti-rollover simulation were the same as those of the anti-sideslip simulation in Figure 6. The road adhesion coefficient $\mu$ of the road was set to 0.85 . The vehicle speed was set to $65 \mathrm{~km} / \mathrm{h}$. The animation effects, lateral displacements, and yaw angles for four different vehicles are shown in Figure 9. The steering angles and four brake cylinder pressures for four different vehicles are shown in Figure 10. The phase trajectories on the roll angle, roll angles, LTR values, sideslip angles, yaw rates, and lateral accelerations for four different vehicles are shown in Figure 11. The $e$ in Figure 11a represents the deviation of the actual roll angle from the expected value.

Figure 9 shows that the red, blue, and green vehicles all experience rollover during turning. However, the white vehicle effectively prevents rollover in trajectory-tracking without losing vehicle speed, and the maximum deviation between the actual lateral displacement and the desired value is controlled within a reasonable range.

As shown is Figure 10, the red vehicle's rollover time is about $15 \mathrm{~s}$, the blue vehicle's rollover time is about $23 \mathrm{~s}$, and the green vehicle's rollover time is about $18 \mathrm{~s}$. For the green vehicle, excessive pursuit of trajectory-tracking accuracy makes too many of the vehicle's vertical loads turn to the right tire when entering the corner, which increases the probability of rollover to the right. For the white vehicle, Figure $10 \mathrm{~g}, 10 \mathrm{~h}$ shows that $u_{4}^{*}<0$ (right turn) when entering the corner, thus reducing the total FWS angles (left turn) and preventing rollover to the right. 
a)

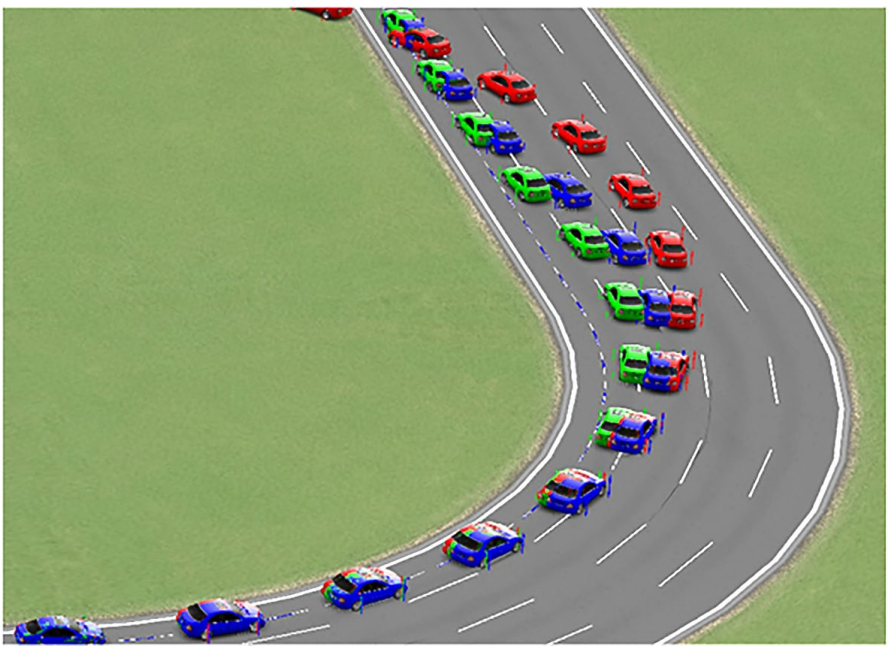

b)

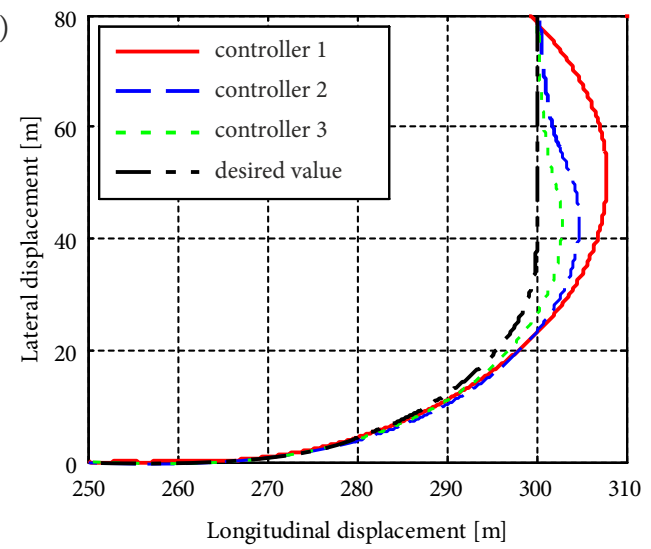

c)

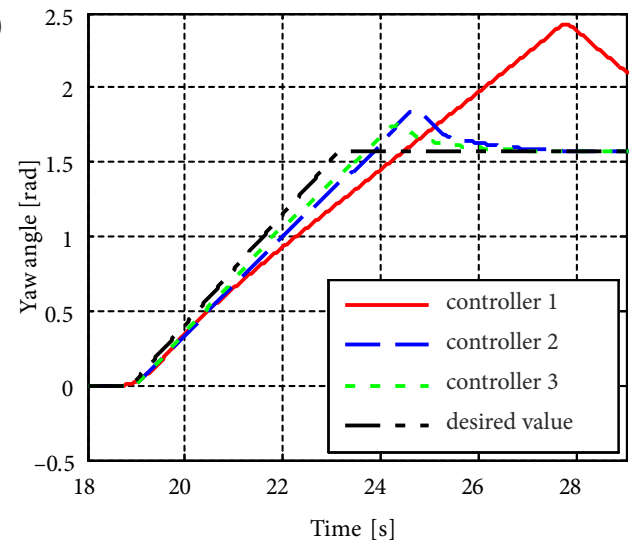

Figure 6. Simulation results in the anti-sideslip simulation: $\mathrm{a}$ - animation effect; $\mathrm{b}$ - lateral displacement; $\mathrm{c}$ - yaw angle

a)

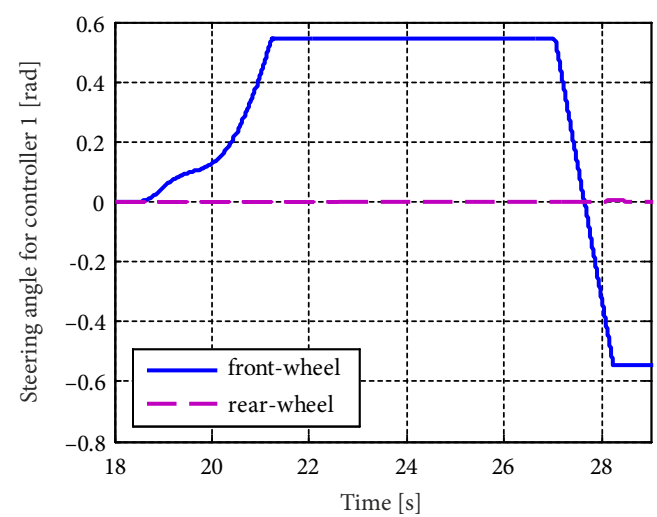

c)

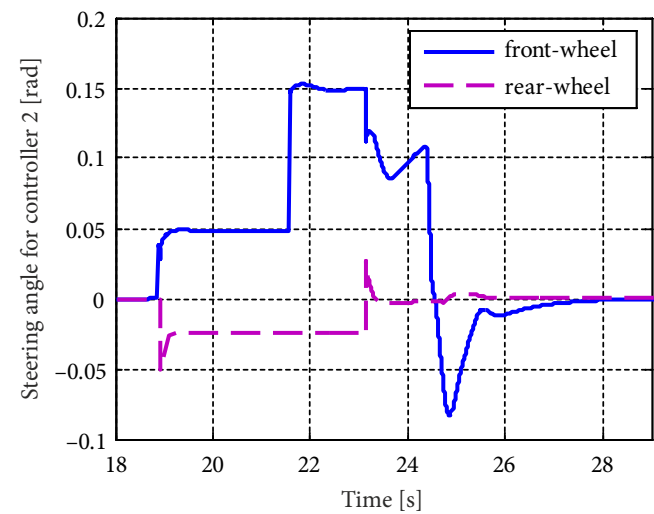

b)

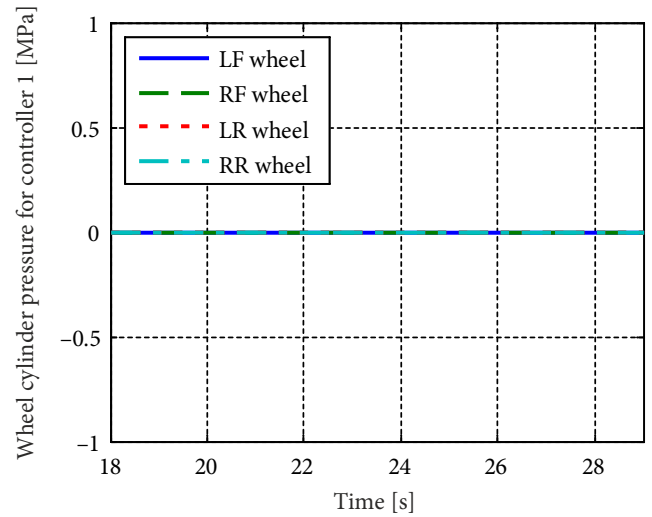

d)

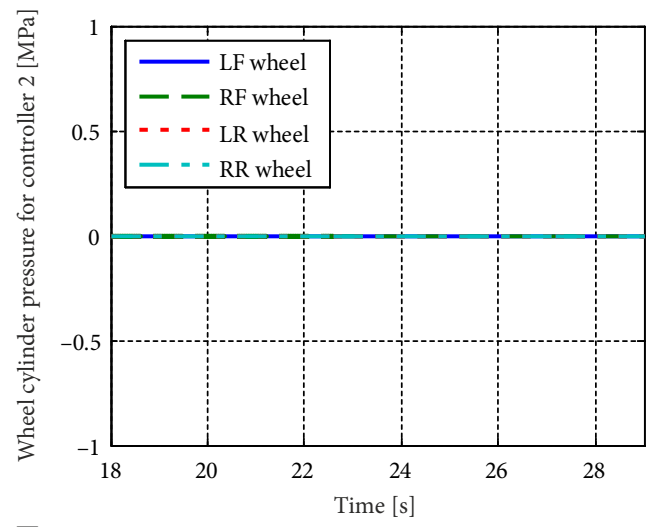

Figure 7. To be continued 
e)

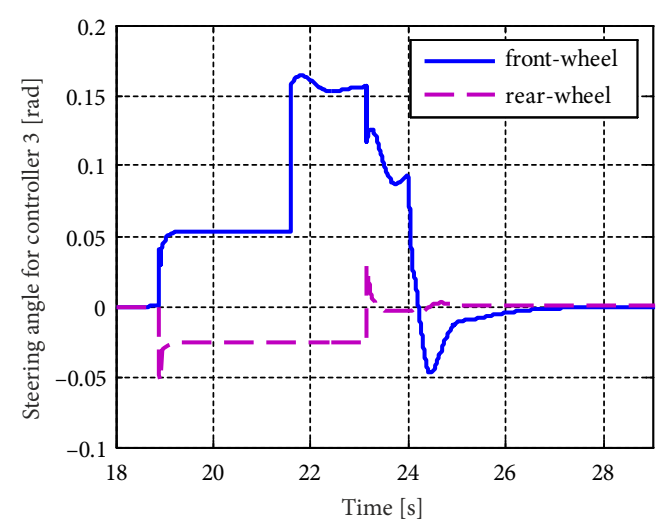

f)

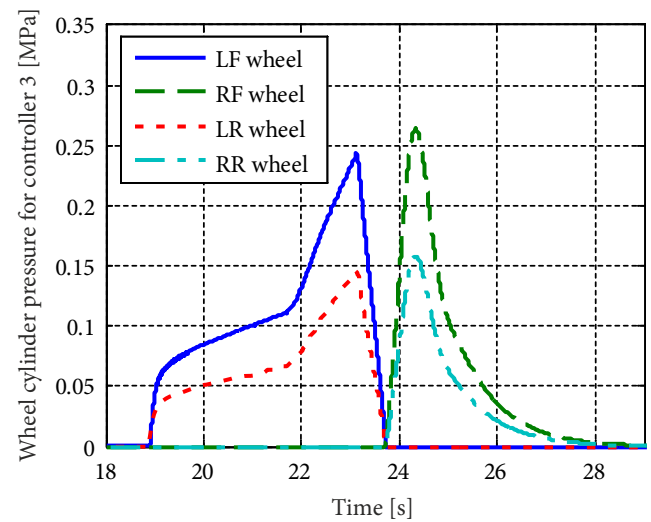

Figure 7. The steering angles and four brake cylinder pressures in the anti-sideslip simulation: $\mathrm{a}, \mathrm{b}$ - red vehicle; $\mathrm{c}, \mathrm{d}$ - blue vehicle; $\mathrm{e}, \mathrm{f}$ - green vehicle

a)

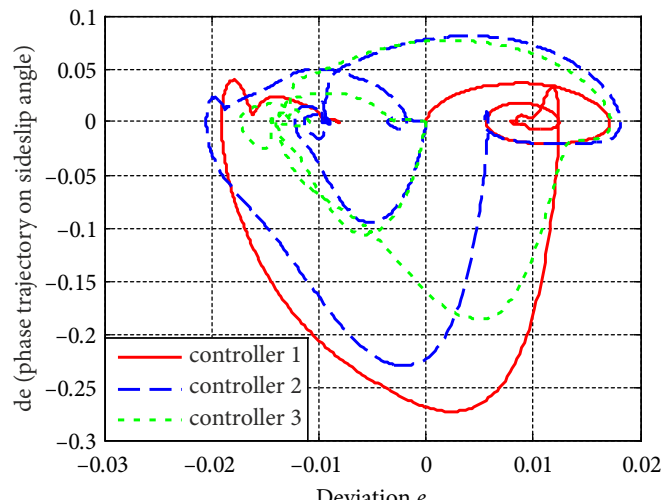

c)

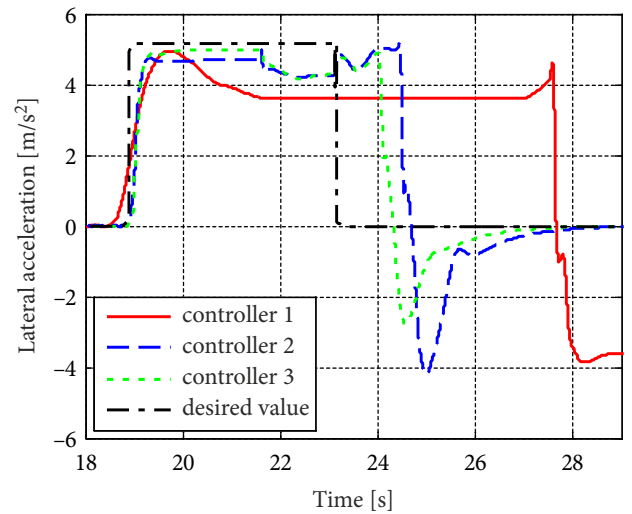

e)

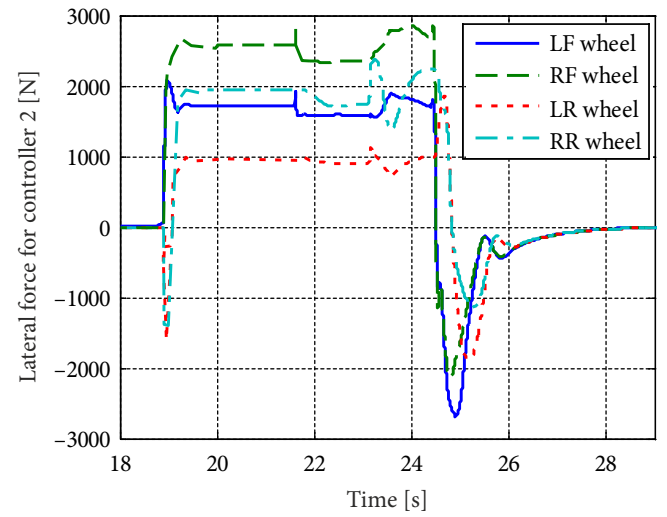

b)

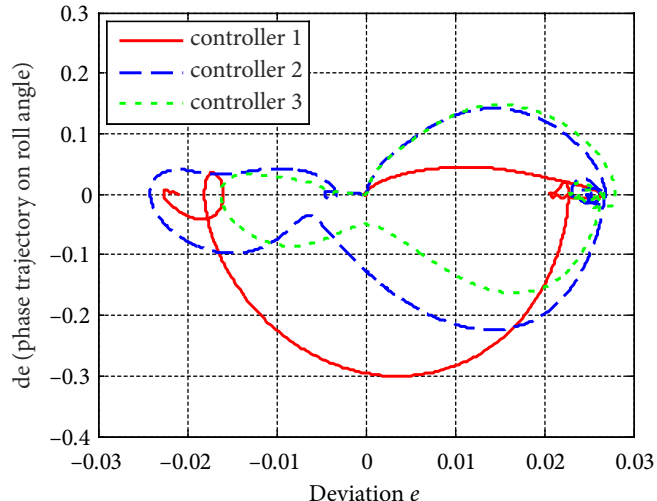

d)

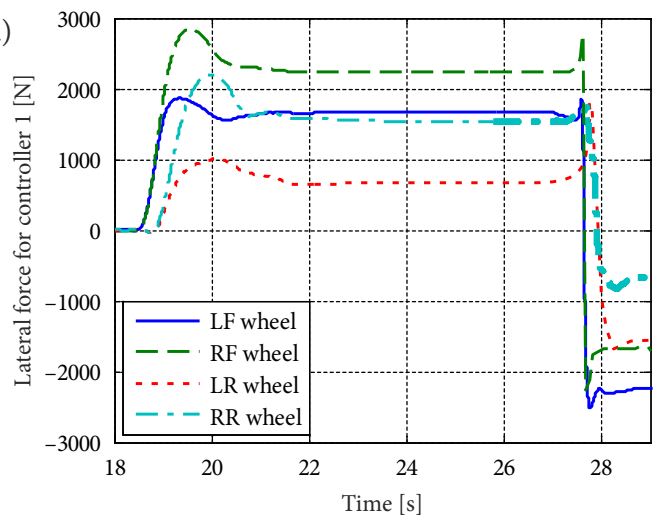

f)

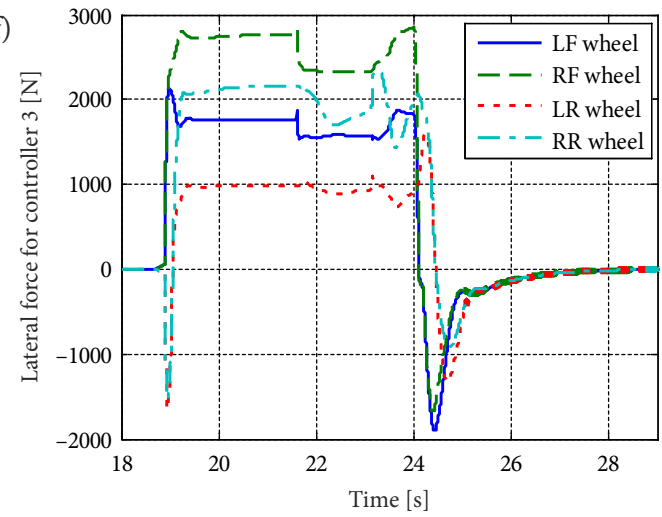

Figure 8. Simulation results in the anti-sideslip simulation: $\mathrm{a}$ - phase trajectories on the sideslip angle; $\mathrm{b}$ - phase trajectories on the roll angle; $c$ - lateral acceleration; $d$ - lateral forces for the red vehicle; $e$ - lateral forces for the blue vehicle; $f$ - lateral forces for the green vehicle 
a)

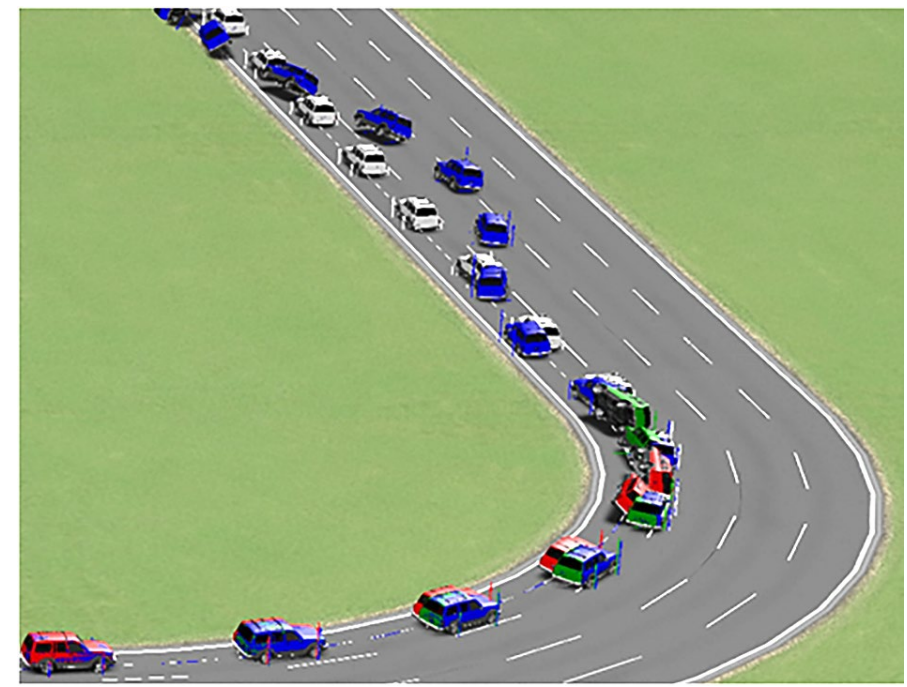

b)

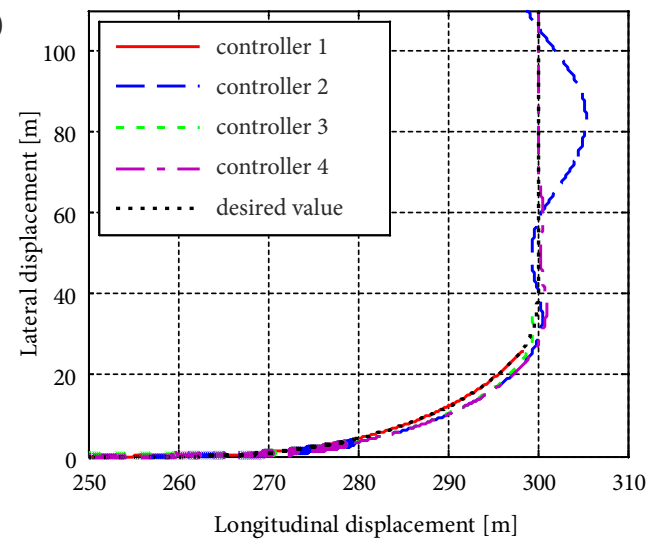

c)

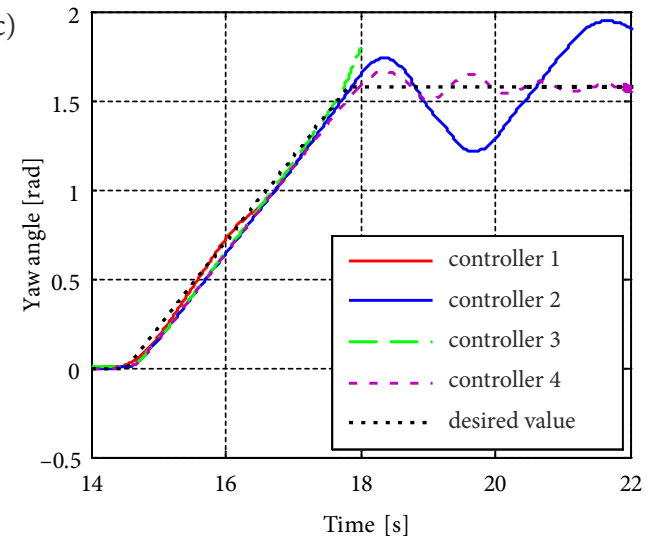

Figure 9. Simulation results in the anti-rollover simulation: $a$ - animation effect; $b$ - lateral displacement; $c$ - yaw angle

a)

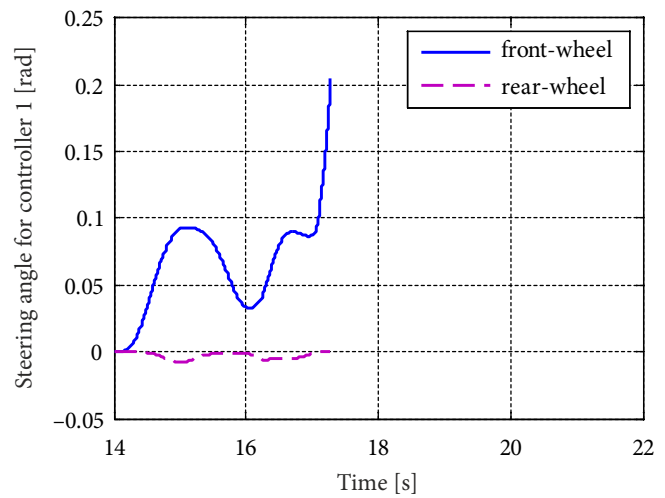

c)

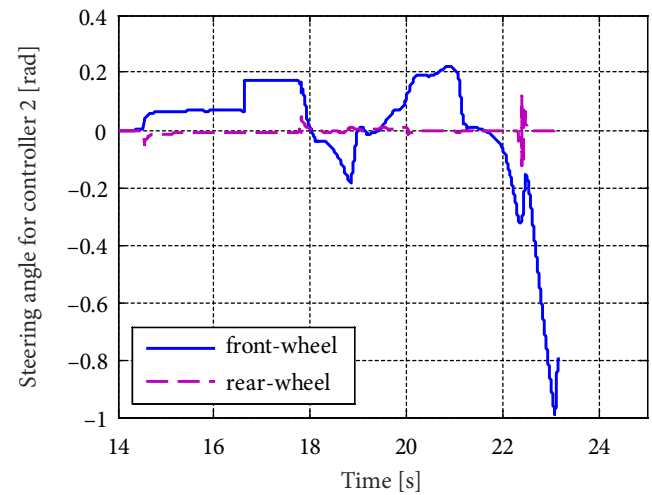

b)

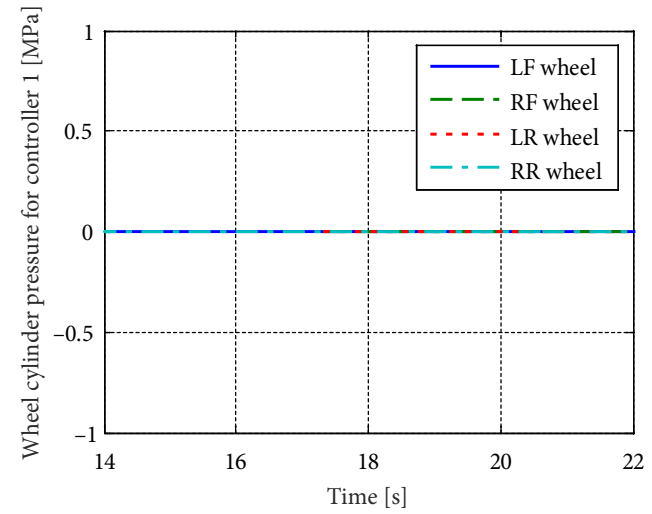

d)

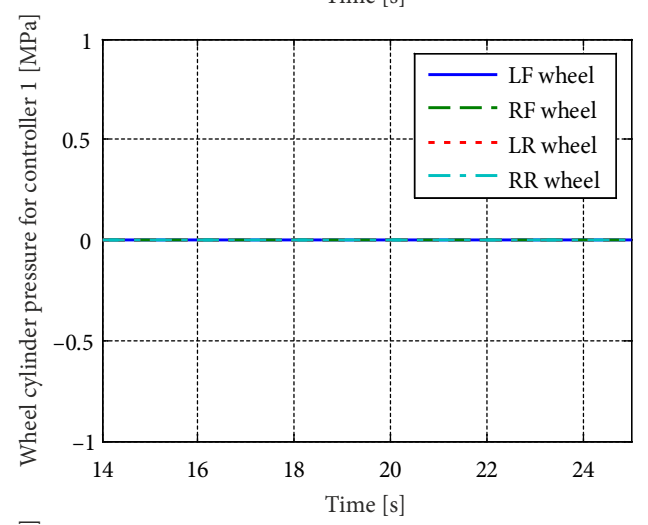

Figure 10. To be continued 
e)

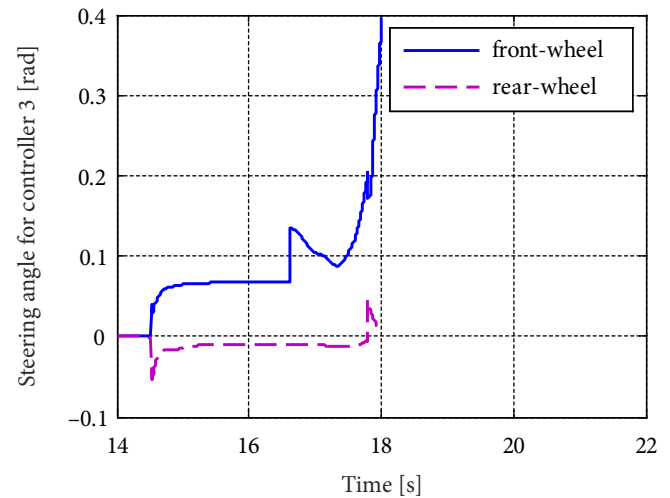

g)

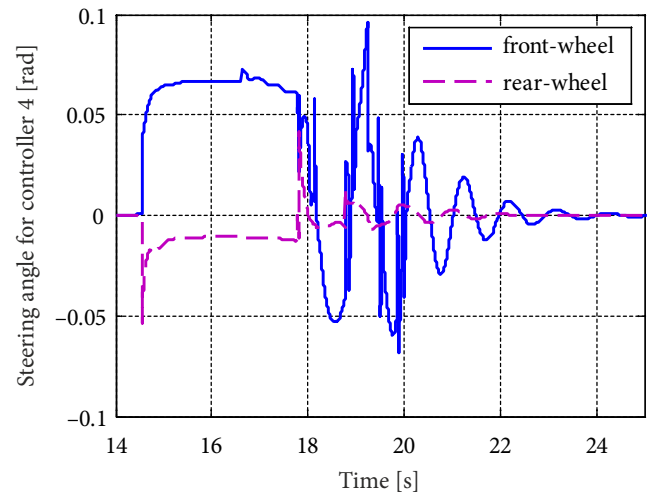

f)

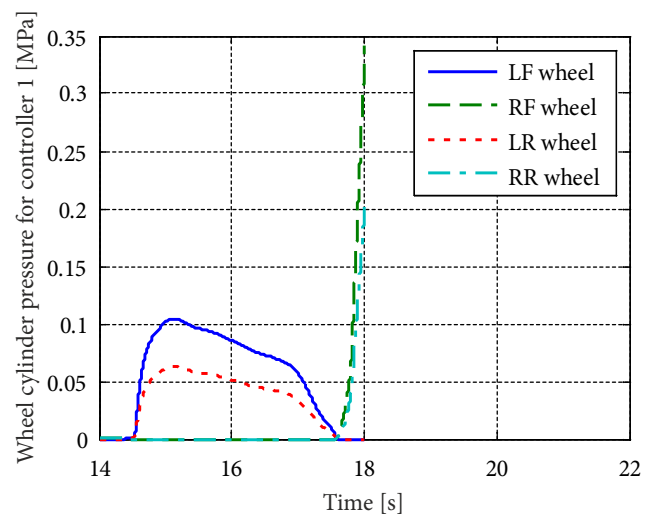

h)

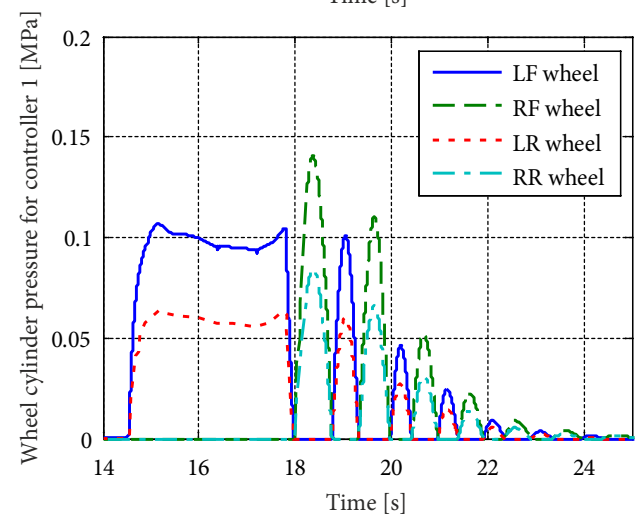

Figure 10. The steering angles and four brake cylinder pressures in the anti-rollover simulation: a, b - red vehicle; c, d - blue vehicle; e, f - green vehicle; $g$, $h$ - white vehicle

Figure 11a, 11b shows that the phase trajectories on the roll angle for the white vehicle are closed, which indicates that controller 4 is stable. Figure 11c shows that the absolute value of LTR for the white car is controlled between 0 and 1 . Figure $11 \mathrm{~d}$ indicates that the sideslip angle of the white vehicle is the smallest. The yaw rate and lateral acceleration values of the white vehicle are closer to the desired values in Figure 11e, 11f. In summary, controller 4 can still prevent rollover in trajectory-tracking without losing vehicle speed, even at high-speeds and small turning radius curved roads.

\section{Conclusions}

The results of this paper can be summarized by the following points:

"»" a conversion method between the target trajectory based on a ground inertial coordinate system and the initial input of the 4WS autonomous vehicle based on a vehicle coordinate system;

"» compared to the FWS trajectory-tracking controller, the 4WS trajectory-tracking controller can more effectively improve safety and stability at high-speeds and on low-adhesion roads;

"»" the trajectory-tracking controller based on an ADRC can more effectively improve the performance of anti-crosswind, anti-sideslip, and anti-rollover in trajectory-tracking compared to the trajectorytracking controller based on an optimal preview;

"» the trajectory-tracking controller based on an ADRC (four channels) can not only track the de- sired lateral displacement, longitudinal displacement, and yaw angle, but also prevent rollover by tracking the desired roll angle;

"»" the real circular bends (single circle center) can be continuously planned and updated depending on the $R, u_{c}, \alpha$, and $\left(X_{0}, Y_{0}\right)$ variables, and the inputs of autonomous vehicles can be adjusted by the trajectory-tracking controller in real time.

Finally, in future work, the suspension system of a 4WS autonomous vehicle in curved trajectory-tracking at high-speeds needs to be further studied.

\section{Acknowledgements and funding}

This work was supported by:

"» National Natural Science Foundation of China (Grant No 51775268);

"» Funding of Jiangsu Innovation Program for Graduate Education of China (Grant No KYLX16_0328);

"» Zhejiang provincial public welfare technology application research project of China (Grant No 2017C35011).

\section{Author contributions}

Runqiao Liu put forward the original concept, proposed the control strategy, and wrote the paper.

Minxiang Wei, Jianwei Wei and Nan Sang gave their valuable suggestions on the research design.

Further, Runqiao Liu, Minxiang Wei, Jianwei Wei, and Nan Sang analysed and discussed the simulation results. 
a)

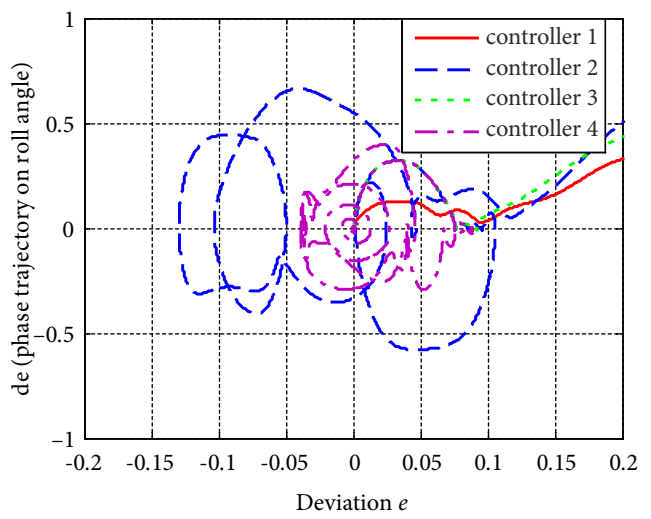

c)

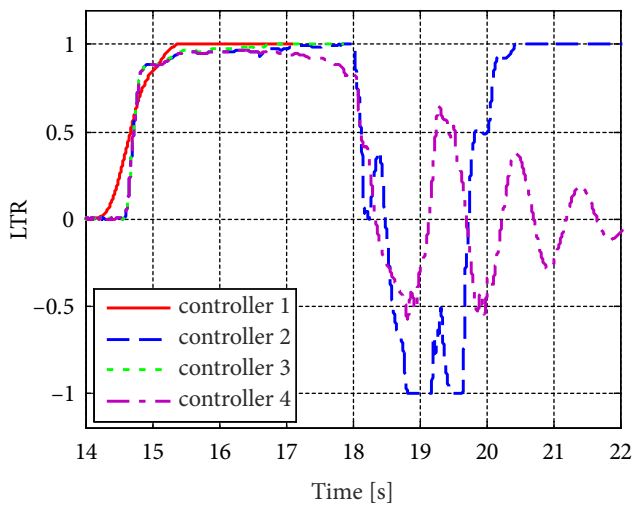

e)

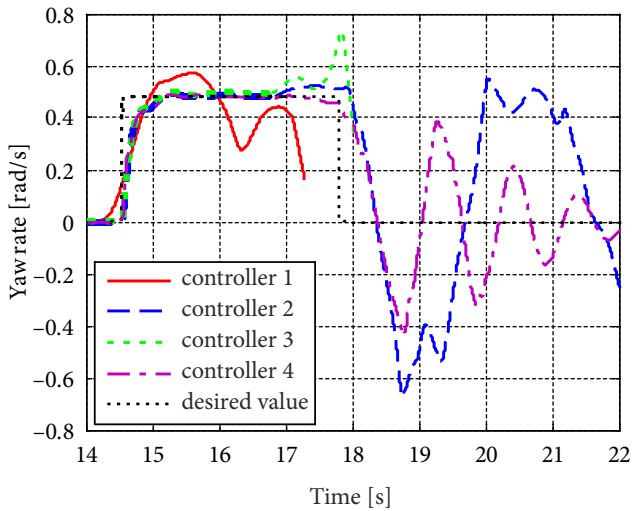

b)

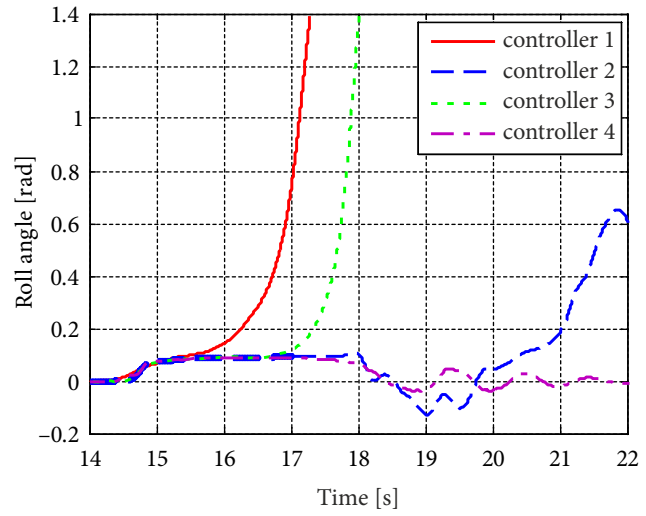

d)

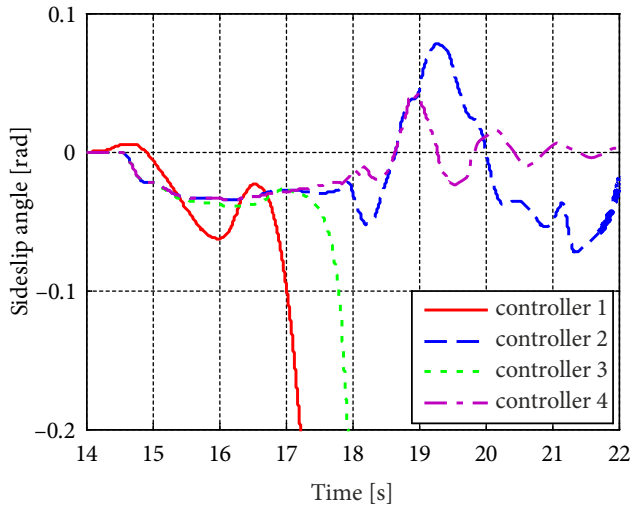

f)

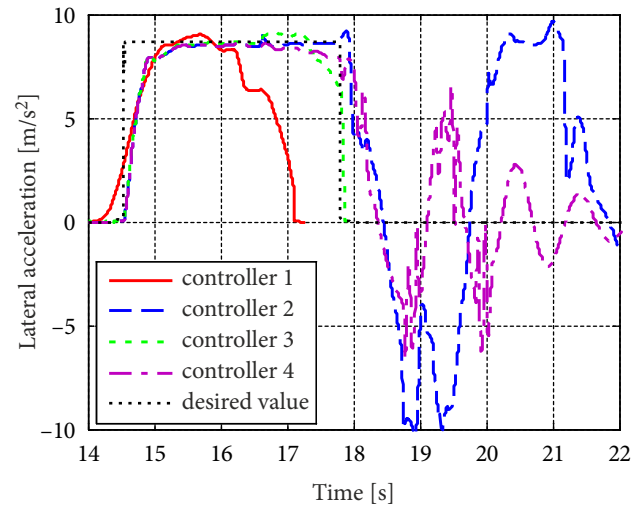

Figure 11. Simulation results in the anti-rollover simulation: a - phase trajectories on the roll angle; $\mathrm{b}$ - roll angle; $\mathrm{c}$ - LTR value; $\mathrm{d}$ - sideslip angle; $\mathrm{e}$ - yaw rate; $\mathrm{f}$ - lateral acceleration

\section{Disclosure statement}

The authors declare no conflict of interest.

\section{References}

Amdouni, I.; Jeddi, N.; El Amraoui, L. 2013. Optimal control approach developed to four-wheel active steering vehicles, in 2013 5th International Conference on Modeling, Simulation and Applied Optimization (ICMSAO), 28-30 April 2013, Hammamet, Tunisia, 1-6. https://doi.org/10.1109/ICMSAO.2013.6552547

Boada, B. L.; Boada, M. J. L.; Díaz, V. 2005. Fuzzy-logic applied to yaw moment control for vehicle stability, Vehicle System Dynamics: International Journal of Vehicle Mechanics and Mobility 43(10): 753-770. https://doi.org/10.1080/00423110500128984

Braghin, F.; Cheli, F.; Corradi, R.; Tomasini, G.; Sabbioni, E. 2008. Active anti-rollover system for heavy-duty road vehi- cles, Vehicle System Dynamics: International Journal of Vehicle Mechanics and Mobility 46: 653-668.

https://doi.org/10.1080/00423110802033064

Cao, J.; Jing, L.; Guo, K.; Yu, F. 2013. Study on integrated control of vehicle yaw and rollover stability using nonlinear prediction model, Mathematical Problems in Engineering 2013: 643548. https://doi.org/10.1155/2013/643548

Chen, X.; Zhang, J.; Yang, M.; Zhong, L.; Dong, J. 2018. Continuous-curvature path generation using Fermat's spiral for unmanned marine and aerial vehicles, in 2018 Chinese Control And Decision Conference (CCDC), 9-11 June 2018, Shenyang, China, 4911-4916.

https://doi.org/10.1109/CCDC.2018.8407982

Cheng, J.; Zhang, Y.; Wang, Z. 2011. Curve path tracking control for tractor-trailer mobile robot, in 2011 Eighth International Conference on Fuzzy Systems and Knowledge Discovery (FSKD), 26-28 July 2011, Shanghai, China, 502-506.

https://doi.org/10.1109/FSKD.2011.6019497 
Chiu, J.; Solmaz, S.; Corless, M.; Shorten, R. 2010. A methodology for the design of robust rollover prevention controllers for automotive vehicles using differential braking, International Journal of Vehicle Autonomous Systems 8(2-4): 146-170. https://doi.org/10.1504/IJVAS.2010.035794

Demirci, M.; Gokasan, M. 2013. Adaptive optimal control allocation using Lagrangian neural networks for stability control of a 4WS-4WD electric vehicle, Transactions of the Institute of Measurement and Control 35(8): 1139-1151.

https://doi.org/10.1177/0142331213490597

Duong, M.-T.; Do, T.-D.; Le, M.-H. 2018. Navigating self-driving vehicles using convolutional neural network, in 2018 4th International Conference on Green Technology and Sustainable Development (GTSD), 23-24 November 2018, Ho Chi Minh, Vietnam, 607-610.

https://doi.org/10.1109/GTSD.2018.8595533

Furukawa, Y.; Yuhara, N.; Sano, S.; Takeda, H.; Matsushita, Y. 1989. A review of four-wheel steering studies from the viewpoint of vehicle dynamics and control, Vehicle System Dynamics: International Journal of Vehicle Mechanics and Mobility 18(1-3): 151-186. https://doi.org/10.1080/00423118908968917

Guo, J.; Chu, L.; Liu, H.; Shang, M.; Fang, Y. 2010. Integrated control of active front steering and electronic stability program, in 2010 2nd International Conference on Advanced Computer Control, 27-29 March 2010, Shenyang, China, 449-453. https://doi.org/10.1109/ICACC.2010.5486880

Han, J. 2009. From PID to active disturbance rejection control, IEEE Transactions on Industrial Electronics 56(3): 900-906. https://doi.org/10.1109/TIE.2008.2011621

Hiraoka, T.; Nishihara, O.; Kumamoto, H. 2004. Model-following sliding mode control for active four-wheel steering vehicle, Review of Automotive Engineering 25(3): 305-313.

Hoffmann, G. M.; Tomlin, C. J.; Montemerlo, M.; Thrun, S. 2007. Autonomous automobile trajectory tracking for off-road driving: controller design, experimental validation and racing, in 2007 American Control Conference, 9-13 July 2007, New York, NY, USA, 2296-2301.

https://doi.org/10.1109/ACC.2007.4282788

J3087_201710. Automatic Emergency Braking (AEB) System Performance Testing. SAE Standard.

Ji, Y.; Guo, H.; Chen, H. 2014. Integrated control of active front steering and direct yaw moment based on model predictive control, in The 26th Chinese Control and Decision Conference (2014 CCDC), 31 May - 2 June 2014, Changsha, China, 2044-2049. https://doi.org/10.1109/CCDC.2014.6852504

Kazemi, M.; Shirazi, K. H. 2012. Handling enhancement of a sliding-mode control assisted four-wheel steer vehicle, Proceedings of the Institution of Mechanical Engineers, Part D: Journal of Automobile Engineering 226(2): 234-246. https://doi.org/10.1177/0954407011416552

Larish, C.; Piyabongkarn, D.; Tsourapas, V.; Rajamani, R. 2013. A New Predictive Lateral Load Transfer Ratio for Rollover Prevention Systems, IEEE Transactions on Vehicular Technology 62(7): 2928-2936. https://doi.org/10.1109/TVT.2013.2252930

Lee, A. 1996. Performance of driver-vehicle in aborted lane change maneuvers, SAE Technical Paper 960516. https://doi.org/10.4271/960516

Li, B; Yu, F. 2010. Design of a vehicle lateral stability control system via a fuzzy logic control approach, Proceedings of the Institution of Mechanical Engineers, Part D: Journal of Automobile Engineering 224(3): 313-326.

https://doi.org/10.1243/09544070JAUTO1279
Li, G.; Hong, W.; Liang, H. 2012. Four-wheel independently driven in-wheel motors electric vehicle AFS and DYC integrated control, SAE Technical Paper 2012-01-0258.

https://doi.org/10.4271/2012-01-0258

Li, J.; Gao, L. 2006. Neural network control approach of vehicle active yaw moment, in 2006 Chinese Control Conference, 7-11 August 2006, Harbin, China, 1714-1717.

https://doi.org/10.1109/CHICC.2006.280829

Liu, R.; Wei, M.; Sang, N.; Wei, J. 2020. Research on curved path tracking control for four-wheel steering vehicle considering road adhesion coefficient, Mathematical Problems in Engineering 2020: 3108589. https://doi.org/10.1155/2020/3108589

Liu, R.; Wei, M.; Zhao, W. 2018. Trajectory tracking control of four wheel steering under high speed emergency obstacle avoidance, International Journal of Vehicle Design 77(1-2): 1-21. https://doi.org/10.1504/IJVD.2018.098265

MacAdam, C. C. 1980. An optimal preview control for linear systems, Journal of Dynamic Systems, Measurement, and Control 102(3): 188-190. https://doi.org/10.1115/1.3139632

MacAdam, C. C. 1981. Application of an optimal preview control for simulation of closed-loop automobile driving, IEEE Transactions on Systems, Man, and Cybernetics 11(6): 393-399. https://doi.org/10.1109/TSMC.1981.4308705

Maruyama, Y.; Yamazaki, F. 2006. Driving simulator experiment on the moving stability of an automobile under strong crosswind, Journal of Wind Engineering and Industrial Aerodynamics 94(4): 191-205. https://doi.org/10.1016/j.jweia.2005.12.006

Ming, T.; Deng, W.; Zhang, S.; Zhu, B. 2016. MPC-based trajectory tracking control for intelligent vehicles, SAE Technical Paper 2016-01-0452. https://doi.org/10.4271/2016-01-0452

Nagai, M.; Hirano, Y.; Yamanaka, S. 1997. Integrated control of active rear wheel steering and direct yaw moment control, Vehicle System Dynamics: International Journal of Vehicle Mechanics and Mobility 27(5-6): 357-370.

https://doi.org/10.1080/00423119708969336

Nagai, M.; Shino, M.; Gao, F. 2002. Study on integrated control of active front steer angle and direct yaw moment, JSAE Review 23(3): 309-315.

https://doi.org/10.1016/S0389-4304(02)00189-3

Nikravesh, P.; Lee, J. 1993. Optimal four-wheel steering strategy using nonlinear analytical vehicle models, SAE Technical $\mathrm{Pa}$ per 931915. https://doi.org/10.4271/931915

Piyabongkarn, D.; Keviczky, T.; Rajamani, R. 2004. Active direct tilt control for stability enhancement of a narrow commuter vehicle, International Journal of Automotive Technology 5(2): 77-88.

Ren, D. B.; Zhang, J. Y.; Zhang, J. M.; Cui, S. M. 2011. Trajectory planning and yaw rate tracking control for lane changing of intelligent vehicle on curved road, Science China Technological Sciences 54(3): 630-642. https://doi.org/10.1007/s11431-010-4227-6

Sang, N.; Wei, M.; Bai, Y. 2015. Control of vehicle active front steering based on active disturbance rejection feedback controller, Transactions of Nanjing University of Aeronautics and Astronautics 32(4): 461-468.

Sano, S.; Furukawa, Y.; Shiraishi, S. 1986. Four wheel steering system with rear wheel steer angle controlled as a function of steering wheel angle, SAE Technical Paper 860625. https://doi.org/10.4271/860625

Shibahata, Y.; Irie, N.; Itoh, H.; Nakamura, K. 1986. The development of an experimental four-wheel-steering vehicle, $S A E$ Technical Paper 860623. https://doi.org/10.4271/860623 
Sirou, M.; Galtier, L. 1991. Rear Steering Control System for a Motor Vehicle with Four Steered Wheels. EP0418115A1. European Patent Office. Available from Internet: https://patents.google.com/patent/EP0418115A1/en

Solmaz, S.; Corless, M.; Shorten, R. 2007. A methodology for the design of robust rollover prevention controllers for automotive vehicles with active steering, International Journal of Control 80(11): 1763-1779.

https://doi.org/10.1080/00207170701473987

Song, J. 2012. Integrated control of brake pressure and rearwheel steering to improve lateral stability with fuzzy logic, International Journal of Automotive Technology 13(4): 563-570. https://doi.org/10.1007/s12239-012-0054-Z

Sun, C.; Zhang, X.; Xi, L.; Tian, Y. 2018. Design of a path-tracking steering controller for autonomous vehicles, Energies 11(6): 1451. https://doi.org/10.3390/en11061451

Sun, T.; Guo, H.; Cao, J.-Y.; Chai, L.-J.; Sun, Y.-D. 2013. Study on integrated control of active front steering and direct yaw moment based on vehicle lateral velocity estimation, Mathematical Problems in Engineering 2013: 275269. https://doi.org/10.1155/2013/275269

Tajima, J.; Yuhara, N.; Sano, S.; Takimoto, S. 1999. Effects of steering system characteristics on control performance from the viewpoint of steer-by-wire system design, SAE Technical Paper 1999-01-0821. https://doi.org/10.4271/1999-01-0821

Urmson, C.; Baker, C.; Dolan, J.; Rybski, P.; Salesky, B.; Whittaker, W.; Ferguson, D.; Darms, M. 2009. Autonomous driving in traffic: boss and the urban challenge, AI Magazine 30(2): 17-28. https://doi.org/10.1609/aimag.v30i2.2238

Wu, Y.; Wang, L.; Li, F. 2018. Research on variable steering ratio control strategy of steer-by-wire system, SAE Technical Paper 2018-01-1583. https://doi.org/10.4271/2018-01-1583

Xia, Y.; Pu, F.; Li, S.; Gao, Y. 2016. Lateral path tracking control of autonomous land vehicle based on ADRC and differential flatness, IEEE Transactions on Industrial Electronics 63(5): 3091-3099. https://doi.org/10.1109/TIE.2016.2531021

Yang, J.; Bao, H.; Ma, N.; Xuan, Z. 2017. An algorithm of curved path tracking with prediction model for autonomous vehicle, in 2017 13th International Conference on Computational Intelligence and Security (CIS), 15-18 December 2017, Hong Kong, China, 405-408. https://doi.org/10.1109/CIS.2017.00094

Yim, S.; Jeon, K.; Yi, K. 2012. An investigation into vehicle rollover prevention by coordinated control of active anti-roll bar and electronic stability program, International Journal of Control, Automation and Systems 10(2): 275-287. https://doi.org/10.1007/s12555-012-0208-9

Zeyada, Y.; Karnopp, D.; El-Arabi, M.; El-Behiry, E. S. 1998. A combined active-steering differential-braking yaw rate control strategy for emergency maneuvers, SAE Technical Paper 980230. https://doi.org/10.4271/980230

Zhang, J.; Zheng, H.; Zhao, M. 2018. Analysis of vehicle steering stability of nonlinear four wheel steering based on sliding mode control, SAE Technical Paper 2018-01-1593. https://doi.org/10.4271/2018-01-1593

Zhao, J.; Taheri, S. 2012. A multi-objective LMI-based antiroll control system, SAE International Journal of Commercial Vehicles 5(2): 421-428. https://doi.org/10.4271/2012-01-1904

Zhou, L.; Ou, L.; Wang, C. 2009. A simulation of the four-wheel steering vehicle stability based on DYC control, in 2009 International Conference on Measuring Technology and Mechatronics Automation, 11-12 April 2009, Zhangjiajie, Hunan, China, 189-193. https://doi.org/10.1109/ICMTMA.2009.469
Zhu, T.; Zong, C. 2009. Research on control algorithm for DYC and integrated control with 4WS, in 2009 International Conference on Computational Intelligence and Natural Computing, 6-7 June 2009, Wuhan, China, 166-169.

https://doi.org/10.1109/CINC.2009.91 